Bryn Mawr College

Scholarship, Research, and Creative Work at Bryn Mawr College

Classical and Near Eastern Archaeology Faculty

Research and Scholarship

Classical and Near Eastern Archaeology

2008

\title{
Nemea Valley Archaeological Project, Excavations at Barnavos: Final Report
}

James C. Wright

Bryn Mawr College, jwright@brynmawr.edu

Evangelia Pappi

Sevasti Triantaphyllou

Mary K. Dabney

Panagiotis Karkanas

See next page for additional authors

Let us know how access to this document benefits you.

Follow this and additional works at: http://repository.brynmawr.edu/arch_pubs

Part of the Classical Archaeology and Art History Commons, and the History of Art, Architecture, and Archaeology Commons

\section{Custom Citation}

Wright, James C., Evangelia Pappi, Sevasti Triantaphyllou, Mary K. Dabney, Panagiotis Karkanas, Georgia Kotzamani, and Alexandra Livarda. 2008. Nemea Valley Archaeological Project, Excavations at Barnavos: Final Report. Hesperia 77:607-654.

This paper is posted at Scholarship, Research, and Creative Work at Bryn Mawr College. http://repository.brynmawr.edu/arch_pubs/61

For more information, please contact repository@brynmawr.edu. 


\section{Authors}

James C. Wright, Evangelia Pappi, Sevasti Triantaphyllou, Mary K. Dabney, Panagiotis Karkanas, Georgia Kotzamani, and Alexandra Livarda 
HESPERIA 77 (2008)

Pages 607-654
NEMEA VALLEY

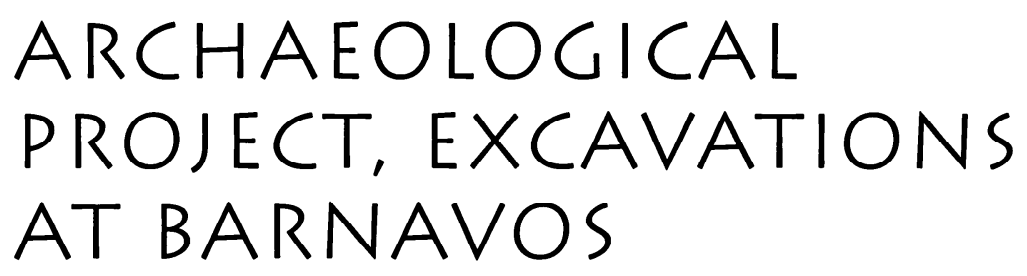

Final Report

$\Sigma \tau \eta \mu v \eta \dot{\mu} \eta \tau \eta \varsigma ~ \Pi \varepsilon \rho \sigma \varepsilon \varphi o ́ v \eta \varsigma \Gamma \alpha \lambda \alpha ́ v \eta$

\section{ABSTRACT}

In 2002 and 2003 the 4th Ephorate of Prehistoric and Classical Antiquities and the Nemea Valley Archaeological Project (NVAP) excavated a robbed Late Helladic (LH) IILA2 chamber tomb at Barnavos, west of the village of Ancient Nemea. Through application of a novel method of stratigraphic analysis and careful documentation of the scattered remains, it was ascertained that the tomb was opened as many as six times for four or five interments, including a child and probably both male and female adults. No other tomb was found in the vicinity. This is the first Mycenaean tomb discovered in the valley, and it belongs to the settlement at Tsoungiza.

This article presents the results of two seasons of excavation of a plundered Mycenaean chamber tomb at Barnavos at Ancient Nemea and a survey of its environs (Fig. 1). ${ }^{1}$ The project was conceived by James Wright, who, in July 2001, was shown the robbed tomb by residents of the village. In consultation with the Ephor, Alexandros Mantis, a joint project was planned with Evangelia Pappi, Epimeletria of Antiquities, representing the 4th Ephorate of Prehistoric and Classical Antiquities. Wright enlisted Sevasti Triantaphyllou and Mary Dabney as codirectors. Together they drew up a
Palaeoanthropology and Speleology of Southern Greece, Ministry of Culture) carried out soil micromorphological analysis (Maria Kousoulaki, Fitch Laboratory, British School of Archaeology, was prevented from participating due to unforeseen circumstances). Palaeobotanical remains were recovered by flotation and examined by Georgia Kotzamani (Ephorate of PalaeoanthroGreece) and Alexandra Livarda (University of Leicester).

Nancy Krahtopoulou visited to examine the geoarchaeological issues pology and Speleology of Southern for further study. Michael Boyd (University of Cambridge) conducted preliminary geophysical prospection. Geoffrey Compton (University of Michigan) was responsible for topographical surveying and GIS analysis. Anastasia Papathanasiou (Ephorate of Palaeoanthropology and Speleology) and Kostas Moraitis (University of Athens) were enlisted for assistance with skeletal analysis. Giorgos Xylapetsidis (Kavalla Museum) conducted all conservation work and was instrumental in site management. Additional acknowledgments are given below. 


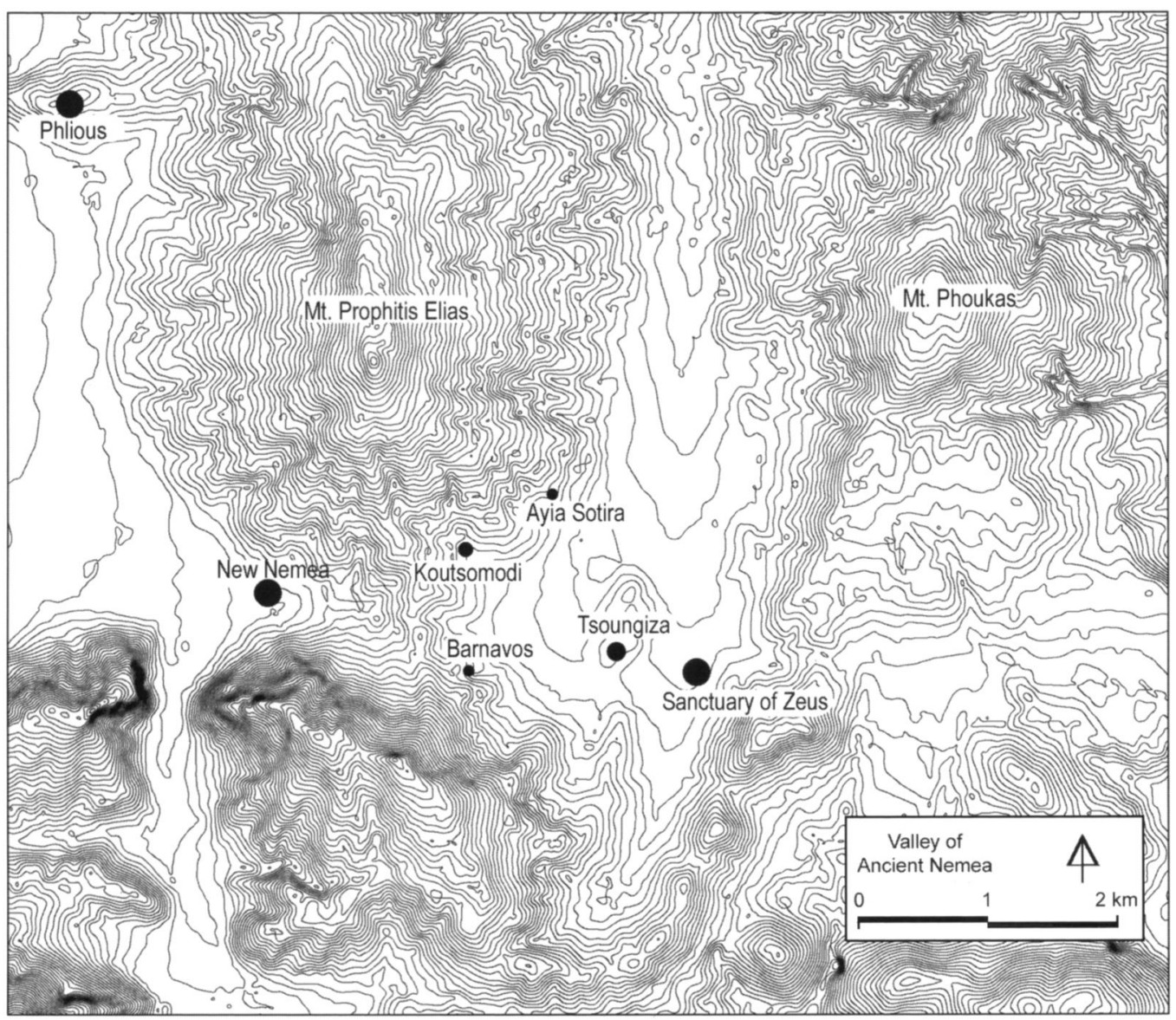

proposal for the project that focused on methodical documentation of all finds in and around the tomb and with special emphasis on a bioarchaeological approach to the burials.

The existence of this tomb near the excavated Mycenaean settlement of Tsoungiza offered an opportunity both to gain information about the population and to compare evidence from one of the cemeteries of Tsoungiza with the extensive record of settlement recovered from its excavation. ${ }^{2}$ Funding was secured, a permit was issued, and excavation began on May 26 and continued through July 6, 2002. Study and processing of finds was conducted throughout the season and continued through July 13, 2002. In 2003 a smaller team supervised excavation of exploratory trenches on both sides of the ravine in which the tomb is located and conducted subsurface survey of a field on the eastern slope of the ravine using ground-penetrating radar. No evidence of other tombs was found. ${ }^{3}$

2. Despite the excavation of scores of Mycenaean chamber tomb cemeteries, there has been little attention to a coordinated project systematically recovering human skeletal material and comparing it to evidence from controlled excavation of the accompanying settlement; cf. Triantaphyllou 2000; Iezzi 2001.
3. Team assistants in 2003 were Jessica Miller and Eliza Wallace from Bryn Mawr College, Dimitri Nakassis from the University of Texas at Austin, and Nicolaus Wright from Reed College. Donald Barber of the Department of Geology, Bryn Mawr College, conducted geophysical prospecting using ground-penetrating radar (GPR).
Figure 1. Map of the Nemea Valley showing locations mentioned in the text. Digital files courtesy Greek Ministry of Agriculture; adapted by G. Compton 


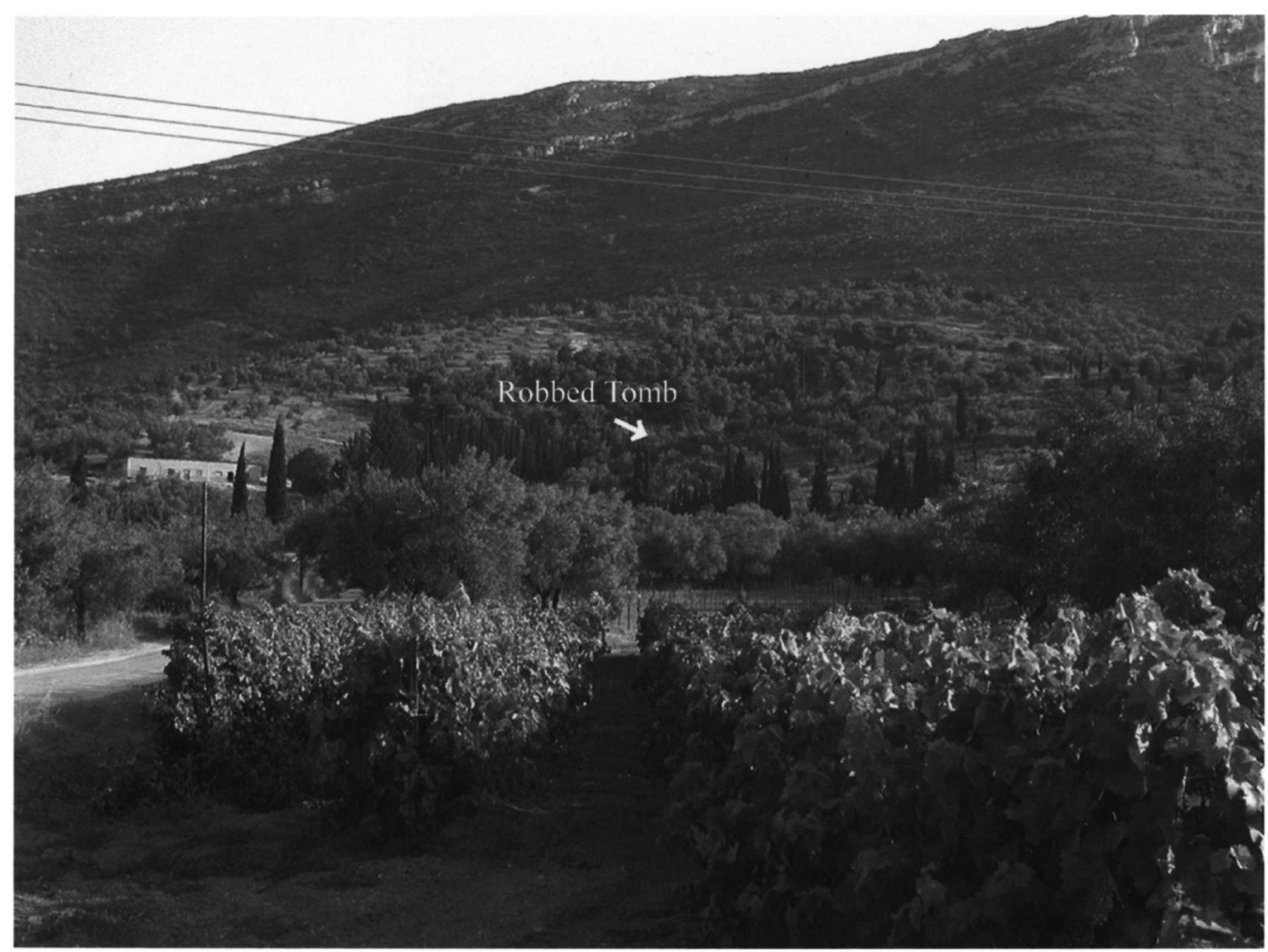

Figure 2. View of Barnavos, looking south. Photo J. C. Wright

\section{THE SITE}

The area known as Barnavos, or Marditsa, is located just west of Ancient Nemea (Figs. 1,2). It is a ravine with a thick growth of cypresses and white pines. The tomb is located on the western hillside just at the edge of the trees. Sherds and human bone fragments could be seen spilling down the slope to the east and southeast, thrown out of the tomb chamber by robbers (Fig. 3). To the northeast the hillside drops away less steeply as the ravine opens out to a field that borders the road to the village (Fig. 4). To the north and west the hill curves around several terraces planted with olives.

The dry streambed of the ravine is deeply incised; directly above to the west is an earlier channel along which a path meanders up through cypresses to the head of the ravine. Above the path the ravine slope is very steep ( $40 \%$ grade) and consists of a caliche palaeosol (asvesti) atop marl (kimilia) interspersed with loosely cemented conglomerate. Higher up the western side of the ravine the land is planted with barley and olives and slopes at about a $20 \%$ grade. It is at the lower east end of this agricultural area that the tomb is located. North and east of the tomb, where modern agricultural activity has transformed the landscape, the hard caliche is not apparent; instead marl predominates, again interspersed with conglomerate. The caliche reappears on the northwest side of the hill as it falls away to another ravine farther west.

On the facing slope east of the tomb is a modern goat-shed, and below it an agricultural road winds up the eastern side of the ravine. Above the shed the lower hillside is planted with barley and olives, and pine forest is present above the road cut. The south slope of the ravine here is very steep 


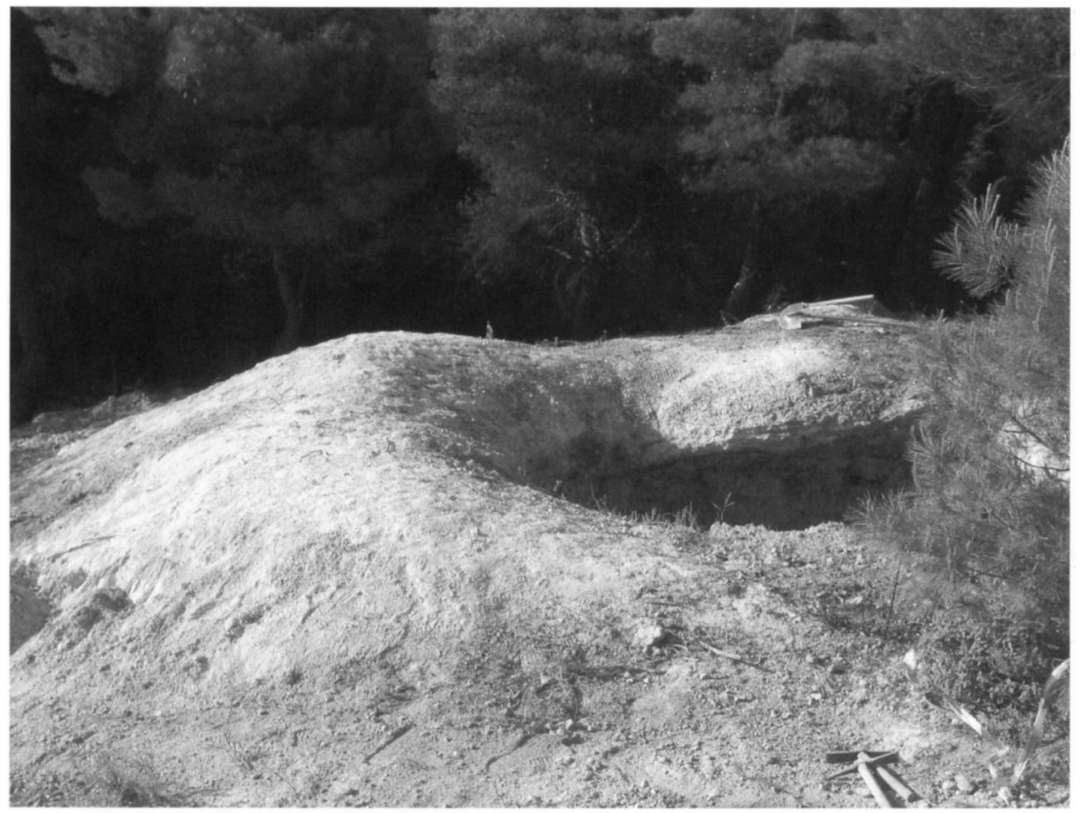

Figure 3. View of spoil heap from robbing of the tomb's chamber, looking south. Photo J. C. Wright

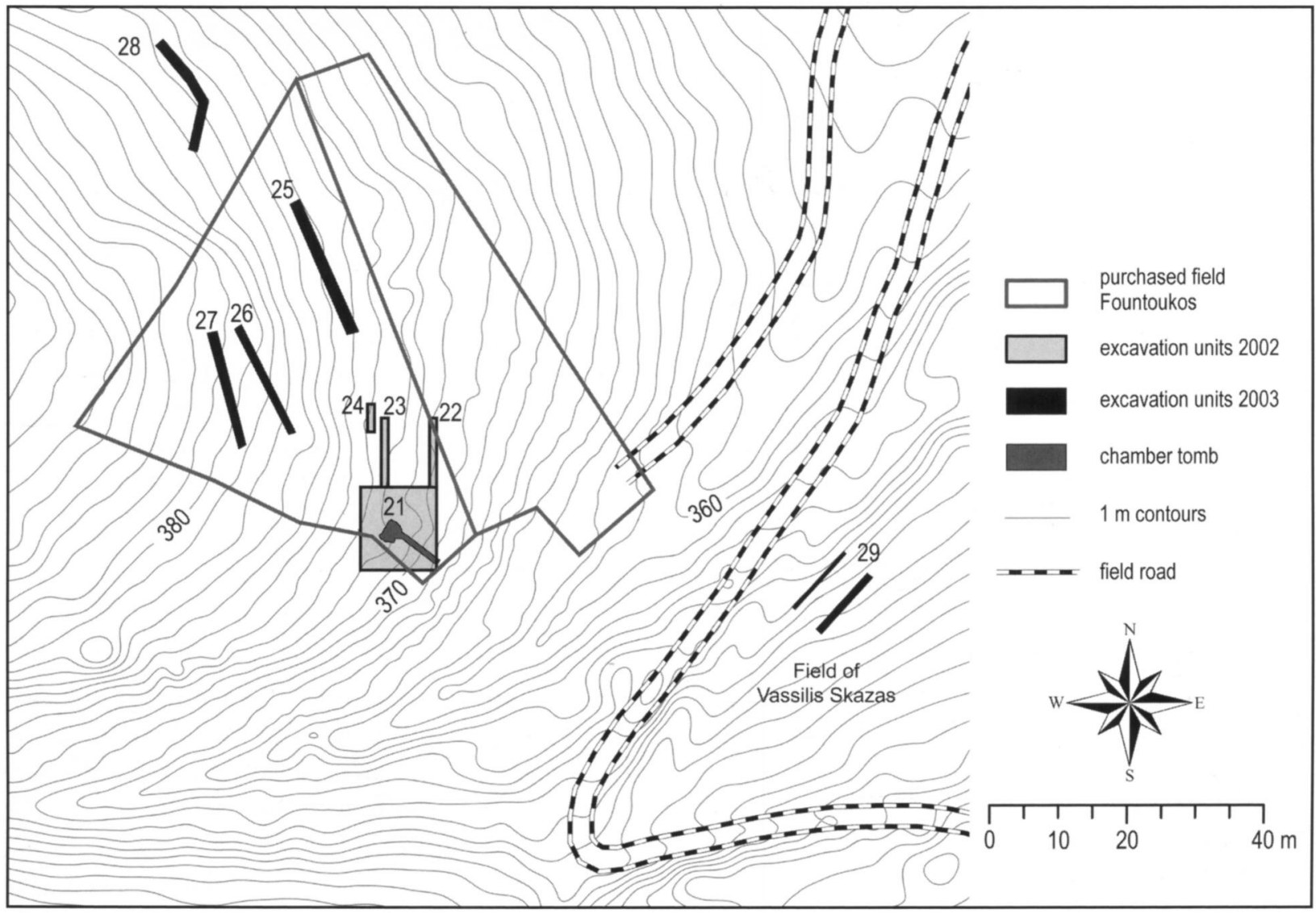

Figure 4. Topographical map of Barnavos area showing the location of excavation units. G. Compton 
and bends westward as it rises to the west (Fig. 4). This slope is even more extensively covered with cypresses and white pine than the opposite side, and again, most of the surface is hard caliche or exposed soft marl.

Throughout this area, especially on the northern and western side of the ravine, were numerous pits and slit trenches dug by robbers in search of tombs. These led us to think there were likely to be many tombs farther up the ravine and around on its southern facing slope. We decided first to make a topographic plan (Fig. 4). This was done by Geoffrey Compton using a Sokkia Set 30 total station in conjunction with the GIS package ArcView 3.0. At the same time, we prepared the tomb site for excavation. The tomb's chamber had collapsed, and considerable plant growth covered the debris left behind by the tomb robbers. It was also apparent that the robbers had dug into the side of the chamber, undermining it in areas where they had penetrated deeply into the marl. As noted above, they created a large spoil heap as they threw soil out of the chamber, and bone and artifact debris spilled down the slope (Fig. 3). It was necessary to excavate this area before beginning work in the chamber, especially because the dromos of the tomb lay somewhere beneath the heap.

\section{THE EXCAVATION}

Excavation at Barnavos began with laying out a grid and clearing the surface around the tomb in order to expose any other tombs. To the south this work was made very difficult by the steep slope covered with dense foliage, pine needles, and an extensive network of roots overlying the caliche palaeosol. Excavation unit (EU) 21 was assigned for the area of the robbed tomb (Fig. 4); it measured $11 \mathrm{~m}$ north-south by $10 \mathrm{~m}$ east-west (N6238-6248, E2068720696). ${ }^{4}$ Beginning with the excavation of the spoil heap outside the collapsed and robbed chamber, we recorded finds according to meter grid designations (square-meter units, or SMU) and stratigraphic units (SU). ${ }^{5}$ All of the area of EU 21 was cleaned to the sterile caliche, and no evidence of other tombs immediately adjacent to the robbed one was discovered.

The robbed tomb in EU 21 resembles most Mycenaean chamber tombs. ${ }^{6}$

4. The system for numbering excavation units (EU) and documenting coordinates follows that established for the excavation of Tsoungiza and described in Wright et al. 1990, pp. 621623. For the Barnavos area, the first EU is 21 , and coordinates follow the civil engineering protocol of listing first the southernmost of the $\mathrm{N}-\mathrm{S}$ coordinates followed by the westernmost of the $\mathrm{E}-\mathrm{W}$ series. The coordinates are those of the Greek geodetic system.

5. Wright et al. 1990, p. 621.

6. For example, tombs XXXII and XXXV at Zygouries (Blegen 1928, pp. 57-59, 62-64); in general, see Cavanagh 1987; Cavanagh and Mee 1998, p. 64 . A 5.7-m-long dromos was cut perpendicular to the slope from southeast to northwest (Figs. 5-8). It has a distinct lip at the entrance from which the floor drops downward. The floor is $0.82 \mathrm{~m}$ wide at its entrance and $0.78 \mathrm{~m}$ wide at the facade of the stomion (Fig. 5). The point where the floor meets the facade of the stomion is $2.10 \mathrm{~m}$ below ground surface (Fig. 6). The stomion itself was barely preserved, and it is unclear if the curved ceiling of the entrance represented the actual form of the lintel cut through the earth or if it was merely the result of collapse. Also, the tomb robbers had penetrated into the stomion from within the chamber as they searched for (and missed) the dromos.

The dromos walls slope inward such that the opening at the top was merely $0.45 \mathrm{~m}$ wide (although prior to the damage done by the deep plow, it may have been even narrower; Figs. 6-8). Nothing remained of the blocking wall that presumably filled the stomion, although some slabs of poros limestone in the disturbed chamber probably came from the blocking wall. 


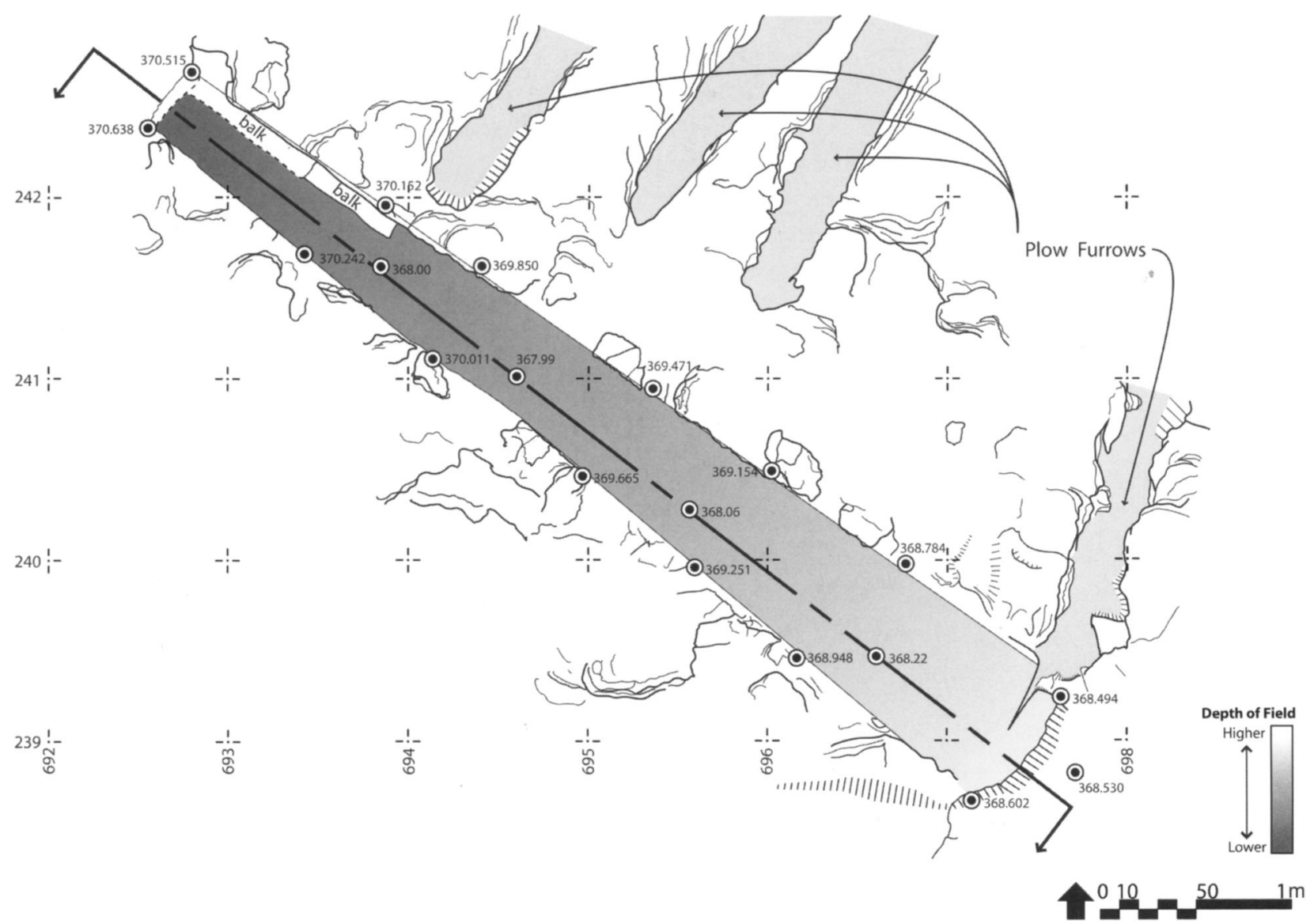

Figure 5. State plan of dromos after excavation. J. C. Wright and N. Wright

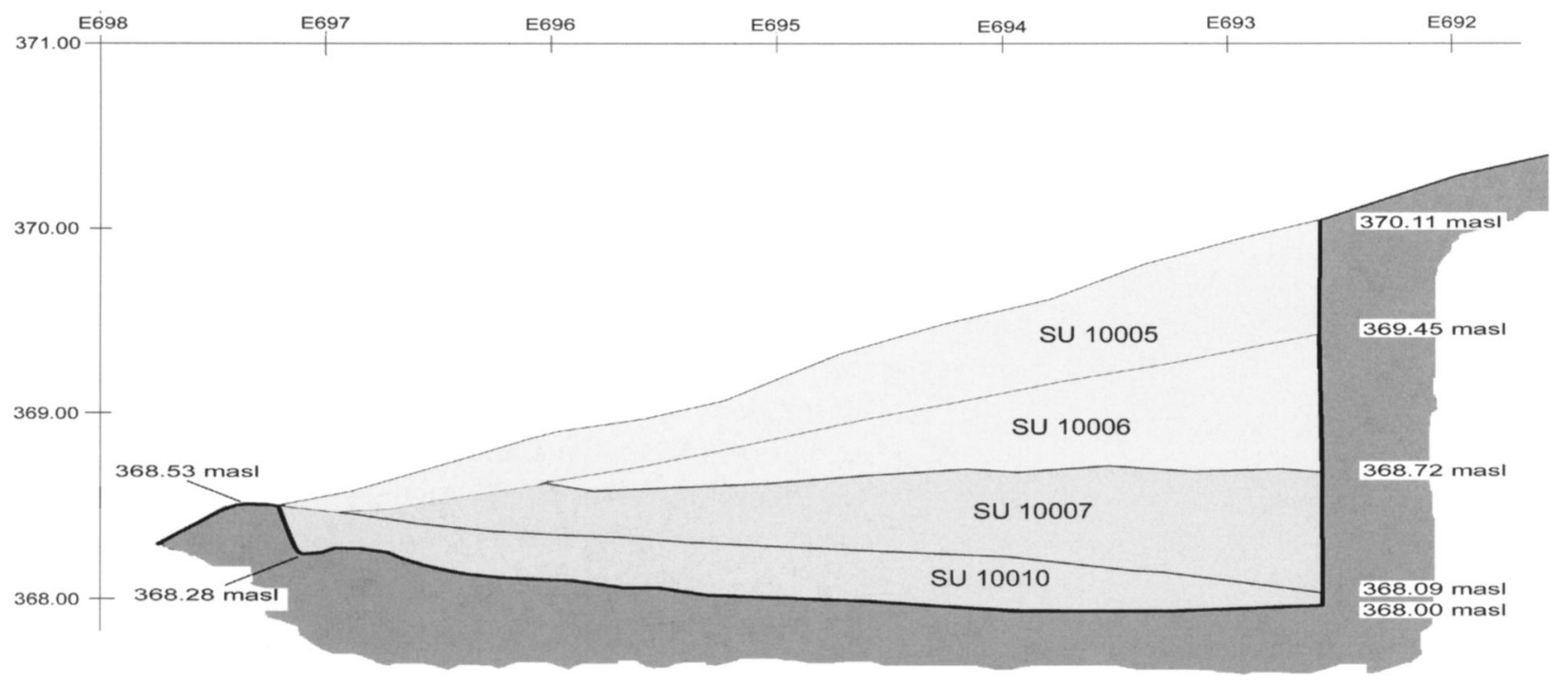

Figure 6. Section through dromos (see Figure 5), looking southwest. J. C. Wright 
Figure 7. Dromos before excavation, looking northwest. Photo J. C. Wright

Figure 8. View of balk in dromos, looking northwest. Photo J. C. Wright
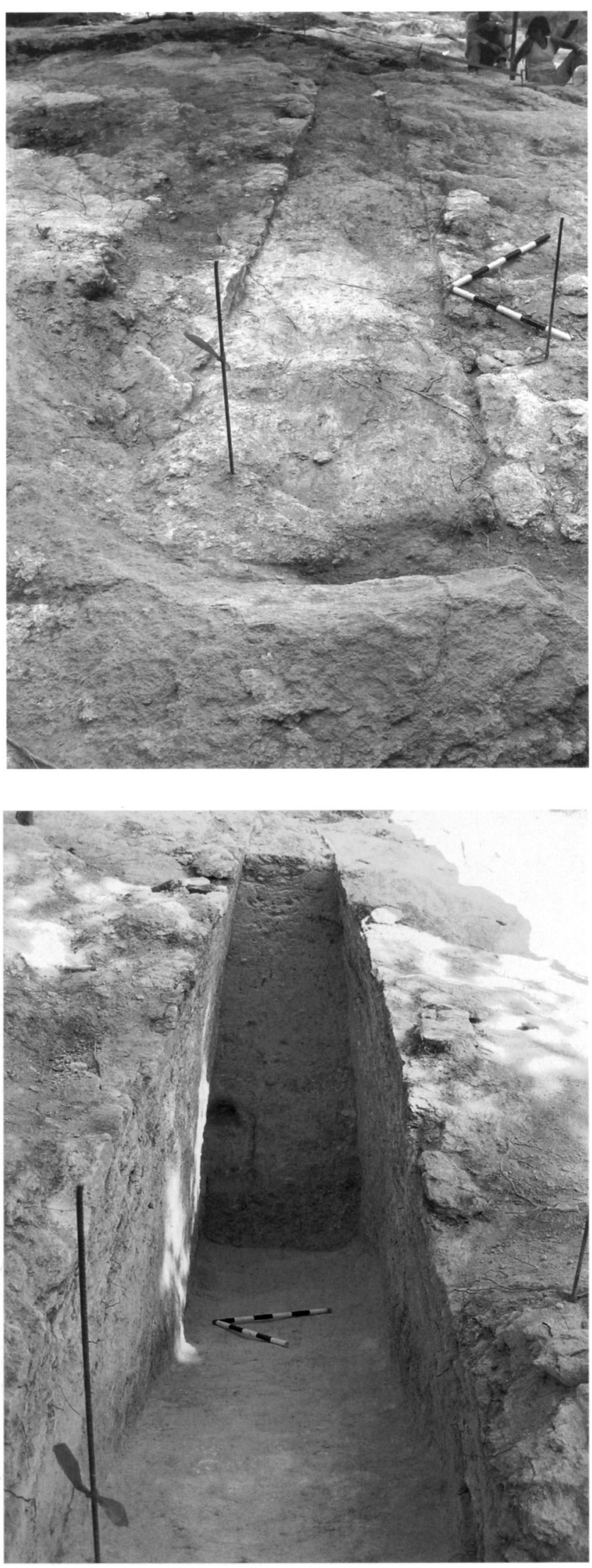


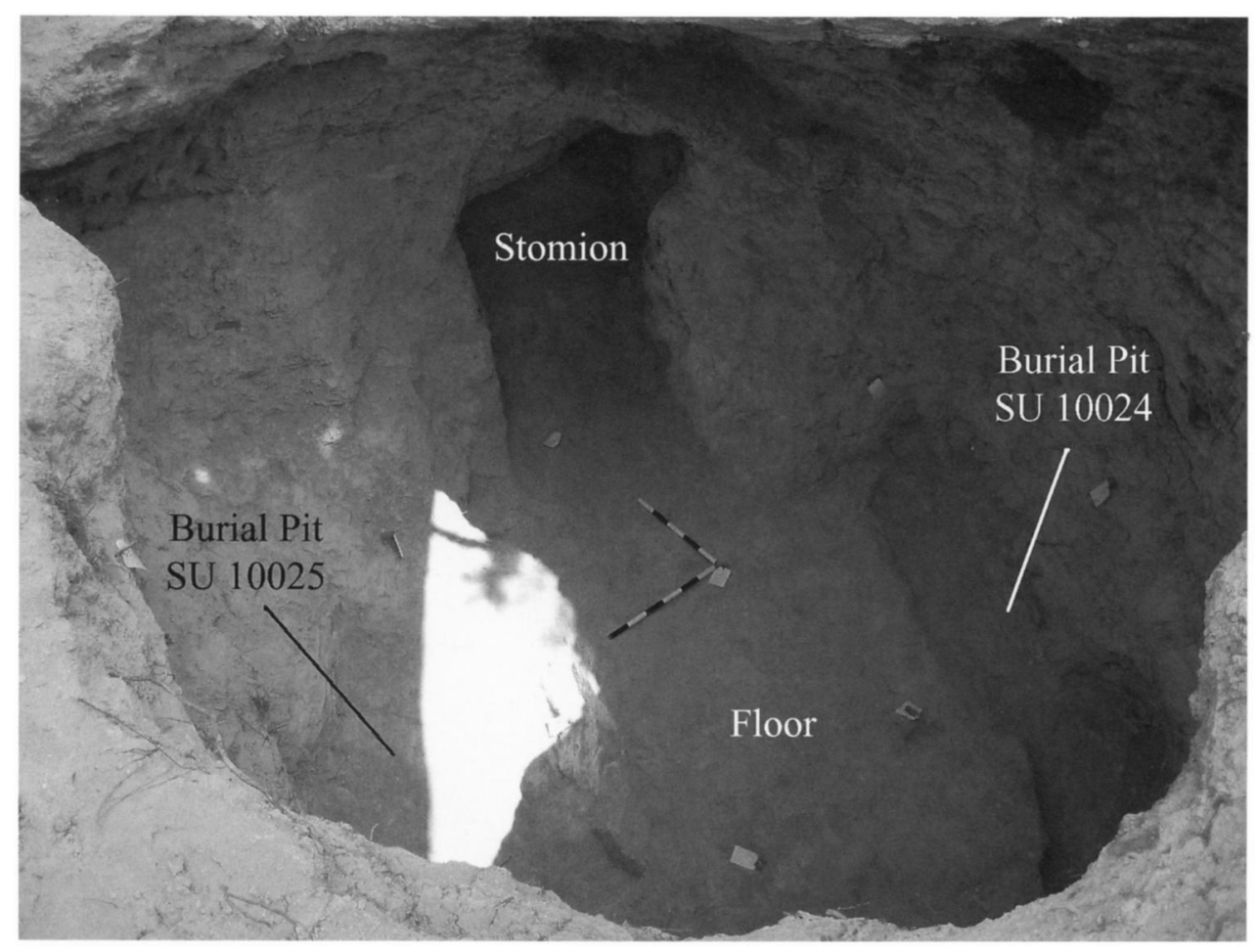

Figure 9. Tomb chamber, from the northwest, looking toward the stomion. Photo J. C. Wright

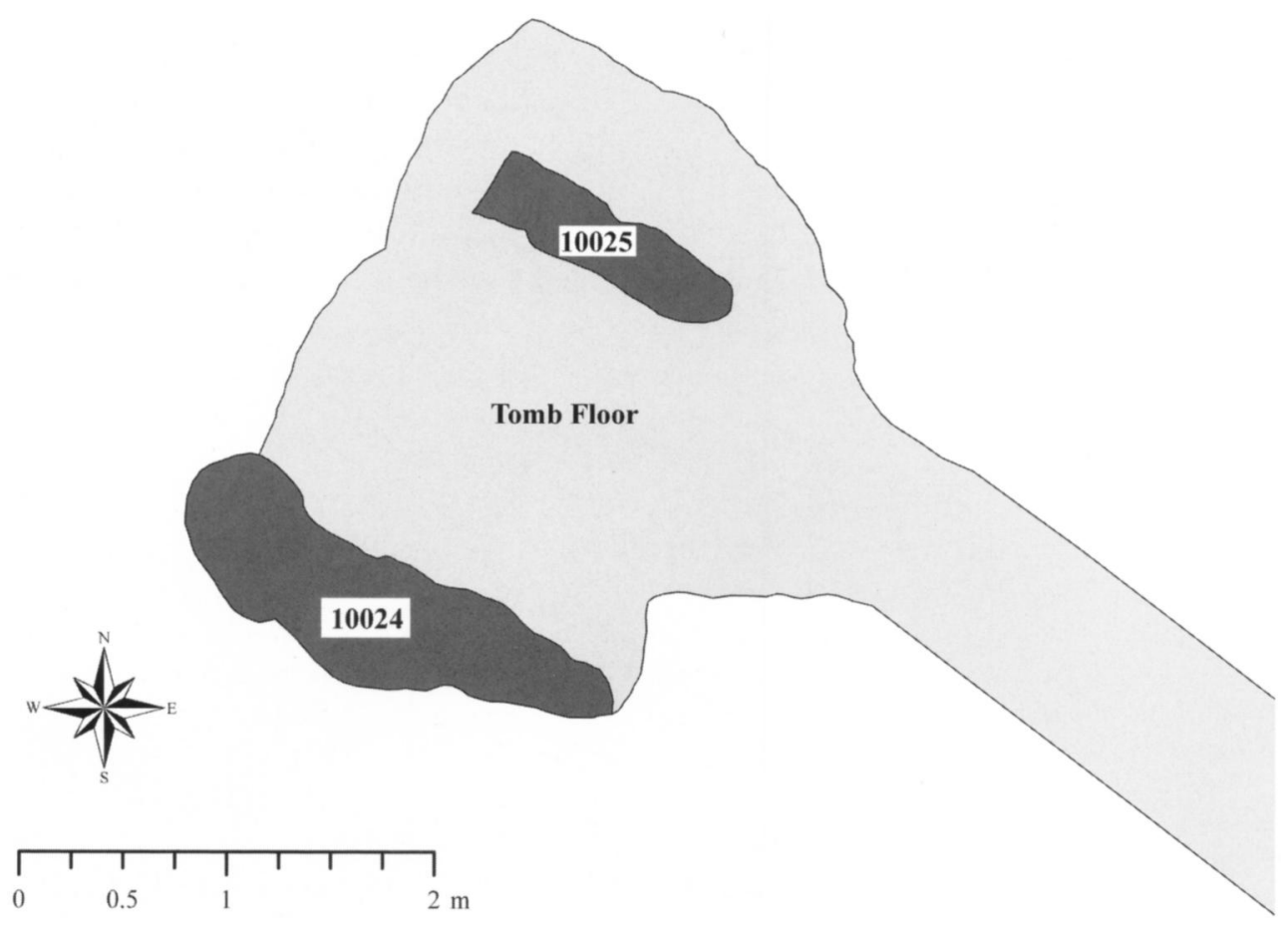

Figure 10. Tomb chamber with burial pits. G. Compton 
The tomb robbers had dug rather deeply in this area, destroying any vestiges of the original form of the entrance into the chamber. The chamber has a maximum excavated breadth of about $4.90 \mathrm{~m}$ but, as can be seen in Figures 9 and 10, it is very irregular because of the depredation of the tomb robbers, who apparently ransacked the chamber in a circular manner, throwing soil behind them as they went. Hence the original, presumably circular, form of the chamber is not recoverable. It was probably not more than $3.75 \mathrm{~m}$ in diameter originally. It is not possible to estimate the interior height of the chamber, although it could not have been as high as ca. $2.35 \mathrm{~m}$, which is the height at which the palaeosol caps the marl. Many Mycenaean chamber tombs are of this size.?

\section{THE DUMP}

We first removed the soil thrown out of the chamber by the tomb robbers, collecting finds according to square-meter units (SU 10001-10004, 10011-10013; Fig. 11). In this way we hoped to provide insight into the process of robbing the chamber and formulate hypotheses about the original disposition of skeletal remains and artifacts. Unfortunately, this approach proved too slow, and we eventually abandoned it in favor of broad areal excavation of the dump surface by stratigraphic unit, but not before having recorded enough data by SMU to gather useful information about distribution. The soil of the dump was largely composed of marl from the contents of the chamber, the collapsed debris filling it, and the tomb robbers' digging into the sides of the chamber. It rested on the humus layer of pine tags, roots, and branches that lay over the caliche.

The artifacts and skeletal remains tossed from the chamber were concentrated at the southern side of the dump. To the extent possible, these are recorded in Figure 11, which distinguishes pottery, bone remains, and other artifacts from each other. The boldface numbers in the key and the symbols representing them on the drawing refer to the catalogued items below. ${ }^{8}$

\section{Catalogue}

1 Piriform jar (FS 45)

Fig. 12

NVAP 10004002. EU 21, SU 10002, 10003, 10004 N239 E691-693, and surface collection from tomb robbers' dump in 2001. P.H. 3.6, max. p.Diam. $14.3 \mathrm{~cm}$.

Fragmentary shoulder. Fine ware, core $7.5 Y R 7 / 3$ pink, surface $2.5 Y 8 / 2$ pale yellow, paint $2.5 \mathrm{Y} 3 / 1$ very dark gray. Linear-painted, three horizontal lines between two horizontal bands below neck and at shoulder.

Late Helladic (LH) IIIA2.

7. See n. 6, above.

8. Whenever possible, dates and Furumark shape (FS) and Furumark motif (FM) attributions are provided for pottery catalogue entries. See Furumark [1941] 1972.
2 Piriform jar?

NVAP 10004004. EU 21, SU 10004 N240 E693. P.H. 1.3, Diam. base $5 \mathrm{~cm}$. Fragmentary ring base, possibly base of 1 . Fine ware, core $10 \mathrm{YR} 7 / 4$ very pale brown, surface 10YR $8 / 3$ very pale brown, paint 10YR $2 / 1$ black. Linear-painted, three horizontal lines between two horizontal bands at base. 


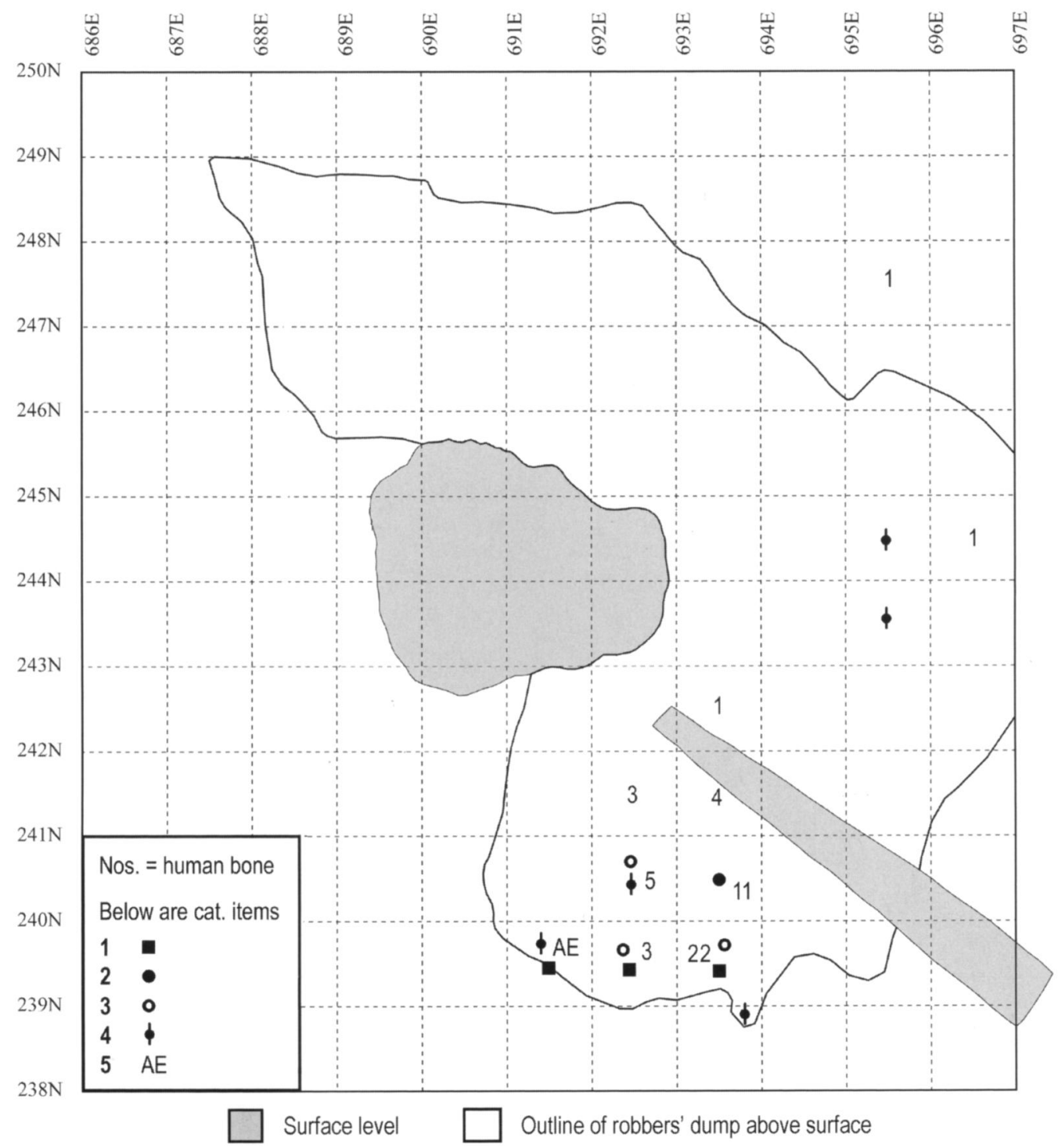

3 Depressed globular stirrup jar (FS 171)

Fig. 12

NVAP 10004003. EU 21, SU 10001, 10002, 10003, 10004 N239 E692-693, N240 E692. P.H. 5.7, max. p.Diam. 9, Diam. base 4, Diam. false neck disk 2.1, Diam. spout rim $1.7 \mathrm{~cm}$.

Restorable. Ring base, flat false neck disk. Fine ware, core 5 YR 7/6 reddish yellow, surface 5YR $8 / 4$ pink, paint 10R 5/8 red. Wavy line (FM 53) in belly zone below and above four horizontal lines between two horizontal bands on shoulder, four horizontal lines between two horizontal bands at base, two bands on spout, two bands on false neck.

LH IIIA2.

4 Jug

Fig. 12

NVAP 10012001. EU 21, SU 10003, 10004 N238 E693, N239 E691, N240 E692; SU 10012 N243 E695, N244 E695. P.H. 17, Diam. rim 10, Diam. base $5.8 \mathrm{~cm}$.

Fragmentary rim, shoulder, and base. Rounded horizontal rim, concave or straight neck, raised flat base. Fine ware, core $2.5 Y$ 8/4 pale yellow, surface $5 Y 8 / 2$ pale yellow. Unpainted.
Figure 11. Diagram of excavation of the dump, showing the finds. G. Compton and J. C. Wright 
Figure 12. Piriform jar 1, stirrup jar 3, and jug 4. Scale 1:3. Drawings N. Wright and K. E. Leaman

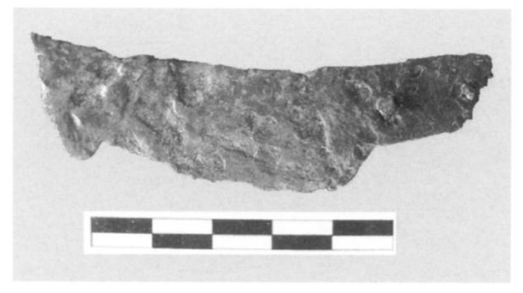

Figure 13. Bronze razor 5.

Photo J. C. Wright

9. Director's notebook, June 15, 2002; the bones were identified by Paul Halstead.

10. One villager claimed that the tomb was robbed by a well-known tomb robber/shopkeeper in Nemea during the 1980 s.

11. NVAP AS survey notebook EII: 28-32, 40-43, 50-51, tract map 648C.
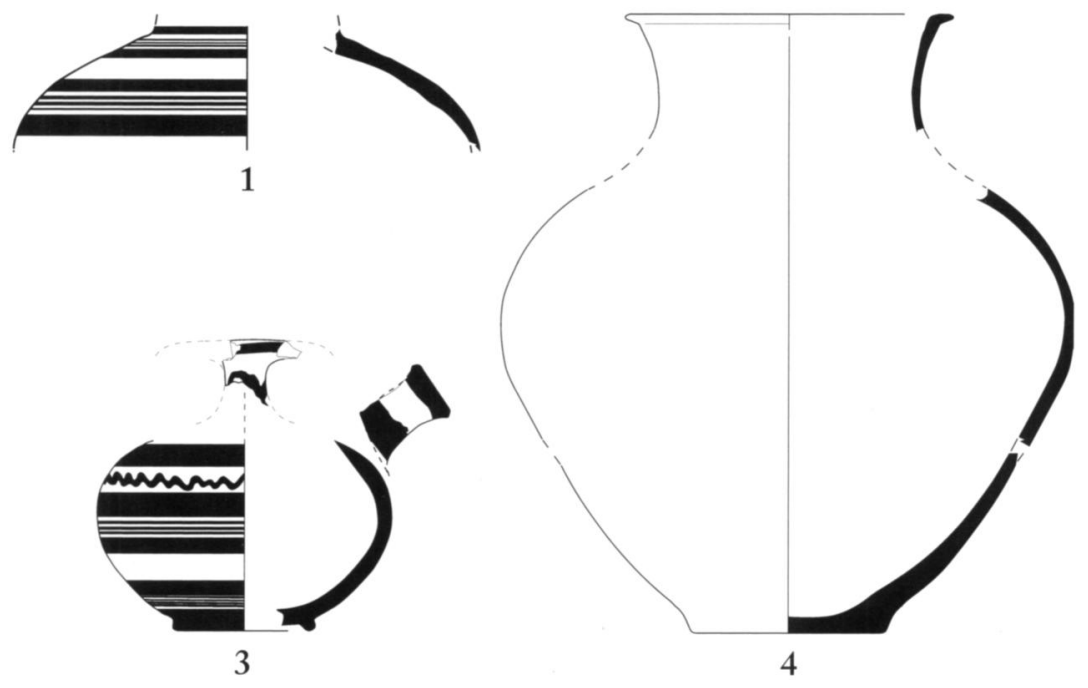

5 Razor

Fig. 13

NVAP 10004001 (also assigned NVAP 10004S001 during excavation). EU 21, SU 10004 N239 E691 (elevation 370.94 masl), and surface collection of tomb robbers' dump in 2001. P.L. 7.6, p.W. 2, Th. 0.2, L. rivet 1, Diam. rivet $0.3 \mathrm{~cm}$.

Restorable. Bronze. Outward curving blade, rectilinear tang, two rivets flattened at opposing ends; rivet closer to blade is larger in diameter than the other.

\section{THE CHAMBER}

Excavation in the chamber was recorded in SU 10022-10025. Our hopes that some portion had not been disturbed were not realized. The entire chamber had been dug out by the tomb robbers, and everything within it was disturbed (Fig. 9). The fill was mostly clean marl consisting of recent collapse and soil the robbers had dug away from the sides of the chamber walls, from a pit that they had excavated into the east side of the chamber, and from an exploratory hole dug through the doorway into the dromos. A large number of stones were collected; many were slabs and blocks not normally found on the hillside. We believe they were stones from the blocking of the dromos.

Among the upper debris from the chamber were the skeletal remains of foxes, who inhabited the chamber after it was robbed. Vassilis Skazas, the owner of the hillside on the other side of the ravine, had informed Wright that he remembered hearing from his father that the tomb had collapsed in the early 1960s and had a lot of brush growing in it where a den of foxes was located. ${ }^{9} \mathrm{He}$ related this story without having heard from us about the animal bones we were finding. Other items associated with the robbing include a rusted hoe blade, many fragments of wax candles, and a wrapper from an Ion chocolate candy bar with a 1994 expiration date. The hoe blade is of a form different from that in use today.

This information leads us to believe that the chamber was robbed more than once, certainly twice: first in the period between the 1960s and the 1980 s, and then again in the early $1990 \mathrm{~s} .{ }^{10} \mathrm{~A}$ search through the field notebooks of the archaeological survey that was conducted in this area in 1984 revealed no mention of an open chamber. ${ }^{11}$ Either the survey team 
completely missed this feature, or it was sufficiently obscured by brush and trees that it was not easily visible.

After cleaning away all of the disturbed soil in the tomb, we found traces of two pits: one on the northern side (SU 10025) and the other on the southern (SU 10024) (Figs. 9, 10). They are oriented lengthwise northwest to southeast. The southern pit actually appears to be two small pits in line, with a total maximum length of $2.30 \times 0.70 \mathrm{~m}$ wide. The northern pit is smaller, about $1.30 \times 0.30 \mathrm{~m}$ wide. Because the chamber floor was disturbed, it is not possible to estimate the depth of the pits. Both were empty, and one cannot ascertain their relation to the finds, although Triantaphyllou notes the proximity of some of the human bone material to them (see below).

\section{Finds from the Chamber}

Pottery found in stratigraphic units inside the chamber, some of which joined fragments from the dromos and the robbers' spoil heap outside the tomb, was presumably originally from the chamber. It belongs mainly to the LH IIIA2 period. Seven out of the 10 fine-ware vessels presumed to be from the chamber are pattern-painted or linear-painted, in contrast to the predominance of unpainted pottery in the dromos (see below). Two fragments of unpainted, medium coarse, cooking-ware jars were also discovered. Closed shapes ( 11 of the 12 identifiable vessels, including alabastra, stirrup jars, piriform jars, and jugs) dominate in the chamber, whereas in the dromos, open shapes (especially kylikes) are predominant.

In addition to the objects from the chamber catalogued below, several other items were also found: one unpainted, fine-ware, angular kylix (FS 267) fragment; three unpainted, fine-ware, unidentifiable vessel fragments; and four unpainted, medium coarse, cooking-ware vessel fragments.

\section{Catalogue}

6 Piriform stirrup jar (FS 167)

NVAP 10023006. EU 21, SU 10001, 10002, 10003, 10004, 10012, 10023 N241-245 E689-691, N241-244 E692, N243-244 E693. P.H. 3.7, max. p.Diam. $15 \mathrm{~cm}$.

Fragmentary shoulder and spout. Fine ware, core $7.5 \mathrm{YR} 7 / 3$ pink, surface 2.5Y 8/2 pale yellow, paint 2.5Y 2.5/1 black. Diagonal Mycenaean flower (FM 18) on shoulder above four horizontal lines between two horizontal bands above group of five horizontal lines.

LH IIIA2-B1.

7 Rounded alabastron (FS 85)

Fig. 14

NVAP 10023008. EU 21, SU 10002, 10003, 10004; SU 10023 N241-244 E689-693. P.H. 3.6, max. p.Diam. at shoulder $10.5 \mathrm{~cm}$.

Fragmentary shoulder with handle. Fine ware, core $10 \mathrm{YR} 7 / 3$ very pale brown, surface $10 \mathrm{YR} 8 / 2$ very pale brown, paint $10 \mathrm{YR} 2 / 1$ black. Row of triangular net patches (FM 42:21) or filled triangles (FM 61A:6-7); stacked arcs fill areas between triangles.

LH IIIA2. 

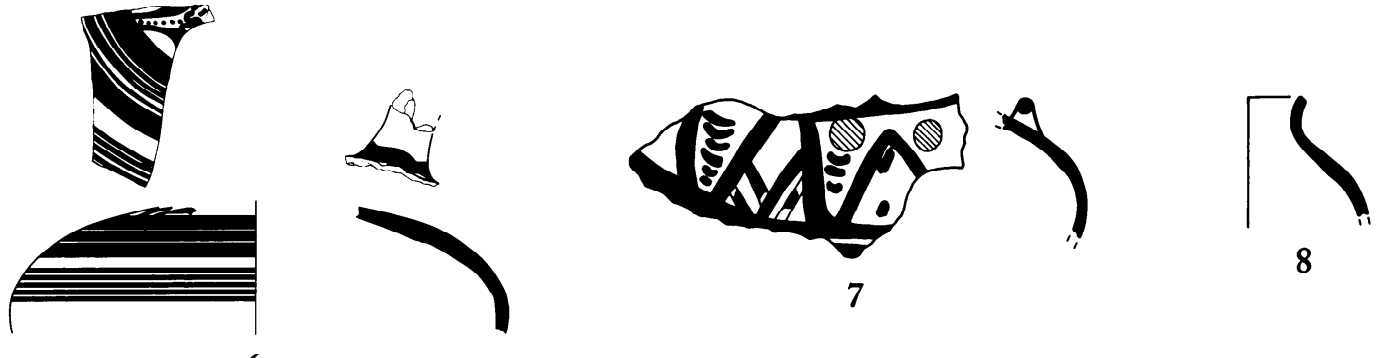

8

Figure 14. Stirrup jar 6, alabastron 7, juglet 8, alabastron 9, cooking jug/ amphora/hydria 10, and jug 11.

Scale 1:3. Drawings N. Wright and K. E. Leaman (6, 9-11), M. K. Dabney and J. E. Pfaff $(7,8)$
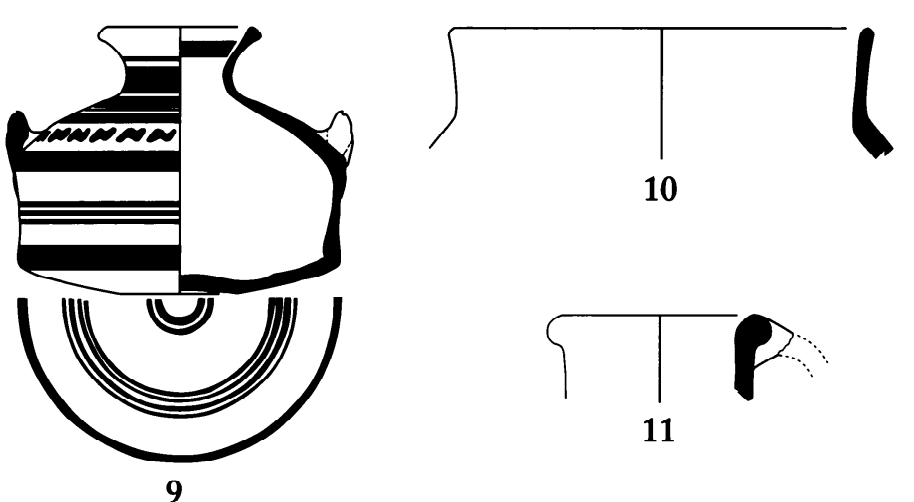

10

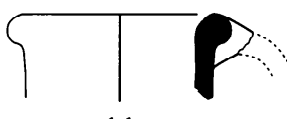

11

8 Juglet (FS 114)

Fig. 14

NVAP 10023015. EU 21, SU 10003; SU 10004 N242 E693; SU 10023 N243

E689, and surface collection from tomb robbers' dump in 2001. P.H. 3.5, est. Diam. rim $3.5 \mathrm{~cm}$.

Fragmentary rim and body, 25\% rim circumference. Spreading rim, rounded shoulder. Fine ware, core and surface N 6/0 gray, paint N 2/0 black, a few white stone inclusions, $<1 \mathrm{~mm}$. Linear-painted, traces of paint on neck and body.

LH IIIA2.

9 Straight-sided alabastron (FS 94)

Fig. 14

NVAP 10023007. EU 21, SU 10001, 10002, 10003, 10004 N239 E691-693; SU 10023 N242 E689-690, and surface collection from tomb robbers' dump in 2001. H. 8, Diam. rim 5, Diam. base $10.1 \mathrm{~cm}$.

Restorable. Fine ware, core 10YR 7/4 very pale brown, surface $2.5 \mathrm{Y} 8 / 3$ pale yellow, paint 2.5Y 2.5/1 black. N-pattern (FM 60:1) on shoulder below four horizontal lines between two horizontal bands, bands at shoulder and base, three horizontal lines at mid-wall, four concentric circles at mid-underside, and two concentric circles at center underside.

LH IIIA2.

10 Cooking jug/amphora/hydria

Fig. 14

NVAP 10023013. EU 21, SU 10004 N242 E693; SU 10023 N242-243 E692. P.H. 4, est. Diam. rim $13 \mathrm{~cm}$.

Fragmentary rim, $7.5 \%$ rim circumference. Straight flaring rim, collar neck. Medium coarse cooking ware, core $7.5 \mathrm{YR} 6 / 4$ light brown, surface $2.5 \mathrm{YR} 4 / 8$ red, sand inclusions, $<2 \mathrm{~mm}$. Unpainted.

Cf. Thomas 2005, pp. 519-521. 
11 Jug

Fig. 14

NVAP 10023014. EU 21, SU 10023 N244-243 E690-691.P.H. 2.5, est. Diam. $\operatorname{rim} 6 \mathrm{~cm}$.

Fragmentary rim and handle, 25\% rim circumference. Rounded rim, vertical handle attached at rim. Medium coarse ware, core $2.5 \mathrm{Y} 5 / 2$ grayish brown, surface 10YR 5/4 yellowish brown, many white and gray (volcanic?) stone and brown ground ceramic inclusions, $<3 \mathrm{~mm}$. Unpainted.

Cf. Thomas 2005, pp. 506-507.

12 Bead

NVAP 10023002. EU 21, SU 10023 N243.90 E692.50, elevation 369.19 masl. L 1.4, Diam. base 2, Diam. apex 0.6, Diam. perforation $0.3 \mathrm{~cm}$.

Intact. Circular conical, straight perforation. Serpentine, very dark red.

\section{THE DROMOS}

Excavation in the dromos was recorded in SU 10005-10008, 10010,1001410015, 10017-10021, and 10026-10030. The dromos was discovered after clearing away the dump and the humus atop the caliche (Figs. 7, 8). It was neatly cut through the caliche. In fact, we discovered a large piece of the caliche (31) that fits the upper end of the dromos and may indicate that the dromos was made by cutting through the caliche with a saw (see Fig. 17, below). Unfortunately, the block is not sufficiently preserved to show any traces of such cutting. We excavated the dromos according to square-meter units and designated one SMU for flotation study. Because we knew that the robbers had dug a hole through the doorway, we maintained a balk about a meter from the end of the dromos in order to avoid contamination with that disturbance (Figs. 5, 8). The disturbed area was excavated in SU 10009 and 10016. The balk also permitted our soil micromorphologist to study the stratigraphy of the dromos (see below).

\section{Finds FROM THE DROMOS}

Because the finds from the dromos come from an undisturbed context, they provide the best evidence for the date of the use of the tomb. All the finds in the dromos belong to the LH IIIA2 period, and most are probably LH IIIA2 late. Seven of these objects $(13,14,16,17,20,21$, and 25$)$ include joining sherds found in the disturbed fill within and outside the tomb-a result of the tomb robbers' tunneling from the chamber into the dromos. Objects including joining sherds from multiple stratigraphic units within the dromos $(18,19$, and 21$)$ support this interpretation of the stratigraphy, because the joining sherds come from stratigraphic units reconstructed as belonging to single depositional layers.

The pottery from the dromos is entirely fine ware, and predominantly unpainted. Of the 17 distinct identifiable vessels, 13 are small open shapes (kylikes and cups). Seven of these are angular kylikes (FS 267). Other shapes include piriform jars $(13,14)$ and a stemmed bowl $(15)$. This pattern is consistent with the finds from other Mycenaean chamber tombs. ${ }^{12}$
12. Unpainted drinking cups were found in many tombs at Mycenae (tombs 502, 505, 514-515, 517-520, $523-525,527,529-531$, and 533 in Wace 1932, see also p. 131) and at Prosymna (tombs VII-X, XII-XIV, XVIII-XXII, XXIV-XXVII, XXXIIXXXIV, XXXVII-XXXIX, XLI-XLIV, XLIX, and LI in Blegen 1937, see also pp. 237-238; Cavanagh and Mee 1998, p. 72; Gallou 2005, pp. 88-96). 


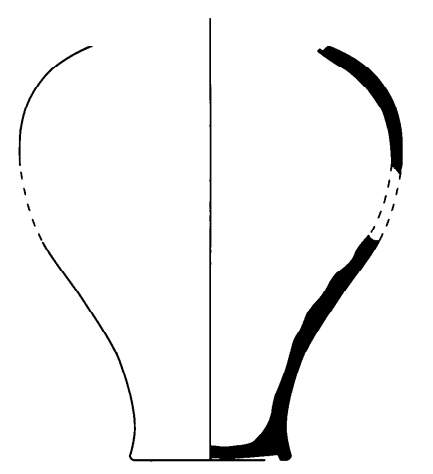

13

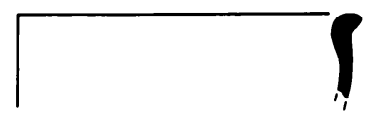

18

Figure 15. Piriform jars 13 and 14, and kylikes 16-19, 23, and 25.

Scale 1:3. Drawings N. Wright and K. E. Leaman $(13,14,17,19,23,25), M$. K.

Dabney and J. E. Pfaff $(16,18)$
13. See, e.g., tomb XLIV at Prosymna: Blegen 1937, p. 214.

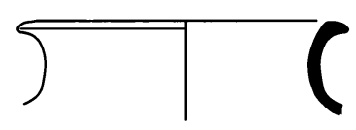

14

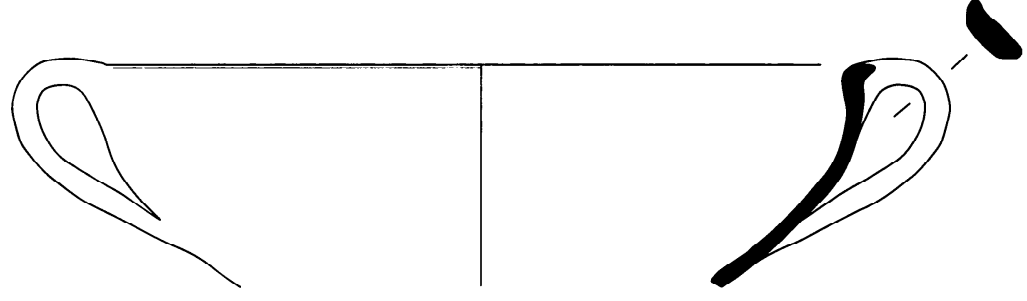

17

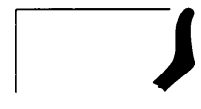

19

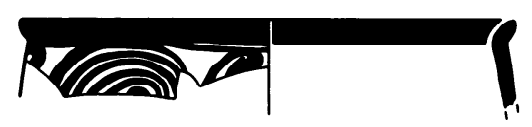

16

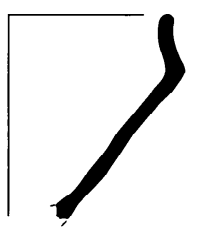

25
In addition to the catalogued objects listed below, the following pottery was also recovered from the dromos: six unpainted, fine-ware, angular kylix (FS 267) fragments; 12 unpainted, fine-ware, open vessel fragments; 21 unpainted, fine-ware, unidentifiable vessel fragments; and 27 unpainted, medium coarse, cooking-ware vessel fragments. The only other object from the dromos is a female figurine (30) that was found up against the northeastern corner of the dromos and facade, a deposition also noted in other chamber tombs. ${ }^{13}$

\section{Catalogue}

13 Piriform jar (FS 45)

Fig. 15

NVAP 10023010. EU 21, SU 10001, 10003; SU 10004 N244 E691; SU 10006 N241 E694; SU 10007 N241 E694; SU 10023 N242 E690, N242 E693, N244 E691. P.H. 12.5, Diam. base $5 \mathrm{~cm}$.

Fragmentary base, lower wall, and shoulder. Small, continuous curve to ring base. Fine ware, core $10 \mathrm{YR} 7 / 3$ very pale brown, surface $2.5 \mathrm{Y} 7 / 3$ pale yellow. Unpainted, polished exterior.

LH IIIA2.

14 Piriform jar (FS 45)

Fig. 15

NVAP 10023011. EU 21, SU 10008; SU 10023 N242-243 E692; nonjoining fragment from SU 10004 based on fabric and shape. P.H. 3, est. Diam. rim $9 \mathrm{~cm}$.

Fragmentary rim and neck, $27.5 \%$ rim circumference. Sloping rim, concave neck. Fine ware, core $2.5 \mathrm{Y} 6 / 2$ light brownish gray, surface $2.5 \mathrm{Y} 7 / 2$ light gray. Unpainted.

15 Stemmed bowl (FS 304)

NVAP 10012002. EU 21, SU 10006 N240 E695; SU 10012. Est. Diam. foot $11 \mathrm{~cm}$. 
Fragmentary foot, 22.5\% foot circumference. Fine ware, core 7.5YR 8/4 pink$2.5 \mathrm{YR} 6 / 6$ light red, surface $10 \mathrm{YR} 8 / 3$ very pale brown, black stone and red ground ceramic inclusions, $<2 \mathrm{~mm}$. Unpainted.

16 Kylix (FS 256)

Fig. 15

NVAP 10023009. EU 21, SU 10007 N241-243 E692-694; SU 10023. P.H.

2.5, Diam. rim $15 \mathrm{~cm}$.

Fragmentary rim, 18\% rim circumference. Fine ware, core 2.5YR 7/6 light red, surface $7.5 \mathrm{YR} 8 / 3$ pink, paint 10R 5/8 red. Curve-stemmed spiral (FM 49)

below rim band in and out.

LH IIIA2 early.

17 Rounded kylix (FS 264)

Fig. 15

NVAP 10027001 (also assigned NVAP 10026001 during excavation). EU 21, SU 10026 N242.48 E692.92 (elevation 370.15 masl); SU 10027. P.H. 6.5, est. Diam. rim $23 \mathrm{~cm}$.

Fragmentary rim, body, and handle, $20 \%$ rim circumference. Fine ware, core $5 Y R$ 7/6 reddish yellow, surface 10 YR $8 / 4$ very pale brown, black stone inclusions, $<1 \mathrm{~mm}$. Unpainted.

LH IIIA2.

18 Rounded kylix (FS 264)

Fig. 15

NVAP 10029003. EU 21, SU 10029. P.H. 2.5, est. Diam. rim $21 \mathrm{~cm}$.

Fragmentary rim, 10\% rim circumference. Fine ware. Unpainted.

LH IIIA2.

19 Angular kylix (FS 267)

Fig. 15

NVAP 10008003. EU 21, SU 10006 N241 E694; SU 10008. P.H. 2.5, est.

Diam. rim $11 \mathrm{~cm}$.

Fragmentary rim and body, $17.5 \%$ rim circumference. Short spreading rim. Fine ware, core 5 YR $6 / 6$ reddish yellow, surface $10 \mathrm{YR} 8 / 3$ very pale brown. Unpainted.

LH IIIA2.

20 Angular kylix (FS 267)

NVAP 10023012. EU 21, SU 10005 N240 E695; SU 10023 N242 E691. P.H. 2.2, est. Diam. rim $14 \mathrm{~cm}$.

Fragmentary rim, $12 \%$ rim circumference. Slightly thickened spreading rim. Fine ware, core $7.5 \mathrm{YR} 7 / 6$, surface $10 \mathrm{YR} 8 / 4$ very pale brown, black and white stone and brown ground ceramic inclusions, $<1 \mathrm{~mm}$. Unpainted.

LH IIIA2 late.

21 Angular kylix (FS 267)

NVAP 10029002. EU 21, SU 10007 N241 E694; SU 10029.P.H. 3, est. Diam. body $13 \mathrm{~cm}$.

Fragmentary rim and body, $15 \%$ body circumference. Fine ware, core $7.5 \mathrm{YR}$ $7 / 4$ pink, surface $10 \mathrm{YR} 7 / 3$ very pale brown. Unpainted.

LH IIIA2.

22 Angular kylix (FS 267)

NVAP 10006004. EU 21, SU 10006. P.H. $4.5 \mathrm{~cm}$. 
Fragmentary rim and body. Short straight rim with slightly spreading lip. Fine ware, core $7.5 \mathrm{YR} 7 / 6$ reddish yellow, surface $10 \mathrm{YR} 8 / 3$ very pale brown, black stone and red ground ceramic inclusions, $<1 \mathrm{~mm}$. Unpainted.

LH IIIA2 late.

23 Angular kylix (FS 267)

Fig. 15

NVAP 10007001. EU 21, SU 10007. P.H. 2.5, est. Diam. rim $10 \mathrm{~cm}$.

Fragmentary rim, $17.5 \%$ rim circumference. Spreading rim with rounded lip. Fine ware, core and surface 7.5YR 7/6 reddish yellow, a few black stone and brown ground ceramic inclusions, $<1 \mathrm{~mm}$. Unpainted.

LH IIIA2.

24 Angular kylix (FS 267)

NVAP 10029001. EU 21, SU 10023 N242-243 E693; SU 10029. P.H. 1.5, est. Diam. rim $10.5 \mathrm{~cm}$.

Fragmentary rim, 25\% rim circumference. Slightly thickened, spreading rim. Fine ware, core 5 YR $7 / 6$ reddish yellow, surface $10 \mathrm{YR} 8 / 3$ very pale brown. Unpainted.

LH IIIA2 late.

25 Angular kylix (FS 267)

Fig. 15

NVAP 10030001. EU 21, SU 10023 N242-243 E692; SU 10030. P.H. 6, est. Diam. rim $10 \mathrm{~cm}$.

Fragmentary rim and body, $45 \%$ rim circumference. Short, spreading rim. Fine ware, core $5 Y R 6 / 6$ reddish yellow, surface $10 \mathrm{YR} 8 / 4$ very pale brown, black stone and red ground ceramic inclusions, $<1 \mathrm{~mm}$. Unpainted.

LH IIIA2 late.

26 Kylix

NVAP 10006001. EU 21, SU 10006 N241.06 E694.74, elevation 369.05 masl. P.H. $5.5 \mathrm{~cm}$.

Fragmentary body. Fine ware, core 7.5YR 6/6 reddish yellow, surface 10YR $7 / 4$ very pale brown. Unpainted.

27 Kylix

NVAP 10008002. EU 21, SU 10008 N241.32 E693.32, elevation 368.37 masl. P.H. 3, Diam. foot $6 \mathrm{~cm}$.

Fragmentary base. Flat string-cut underside. Fine ware, core $10 \mathrm{YR} 7 / 4$ very pale brown, surface 7.5YR 6/8 reddish yellow. Unpainted.

28 Bowl, cup, or kylix

NVAP 10006002. EU 21, SU 10006 N241 E694. P.H. 4.5, est. Diam. rim $16 \mathrm{~cm}$.

Fragmentary rim and body, $7.5 \%$ rim circumference. Spreading rim. Fine ware, core $5 \mathrm{YR} 6 / 6$ reddish yellow, surface $10 \mathrm{YR} 8 / 3$ very pale brown, black stone and red ground ceramic inclusions, $<2 \mathrm{~mm}$. Unpainted.

29 Bowl or cup

NVAP 10030002. EU 21, SU 10030. P.H. 4, est. Diam. rim $17 \mathrm{~cm}$.

Fragmentary rim and body, $10 \%$ rim circumference. Spreading rim. Fine ware, core and surface 5 Y 7/2 light gray. Unpainted. 

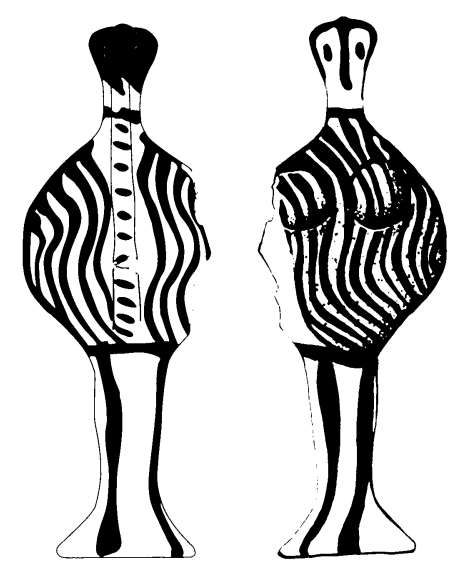

30 Female figurine, Phi type B

NVAP 10008001. EU 21, SU 10008 N241.77 E693.97, elevation 368.43 masl. H. 10.8, Diam. base $2.9 \mathrm{~cm}$.

Complete. Fine ware, core $2.5 \mathrm{Y} 7 / 2-7 / 4$ light gray-pale yellow, surface $5 \mathrm{Y}$ $8 / 2$ pale yellow, paint $5 Y 2.5 / 2$ black. Painted eyes, horizontal lines on plastic plait, vertical wavy lines on torso, low waistband, four vertical lines on stem that curve at base.

\section{LH IIIA2-B.}

31 Fragment of block

Fig. 17

NVAP 10006003. EU 21, SU 10006 N242.40 E692.60. Max. p. dim. $30 \mathrm{~cm}$.

Block cut from dromos suggesting the possible use of a saw as a construction tool. Caliche. Found in dromos area disturbed by tomb robbers.

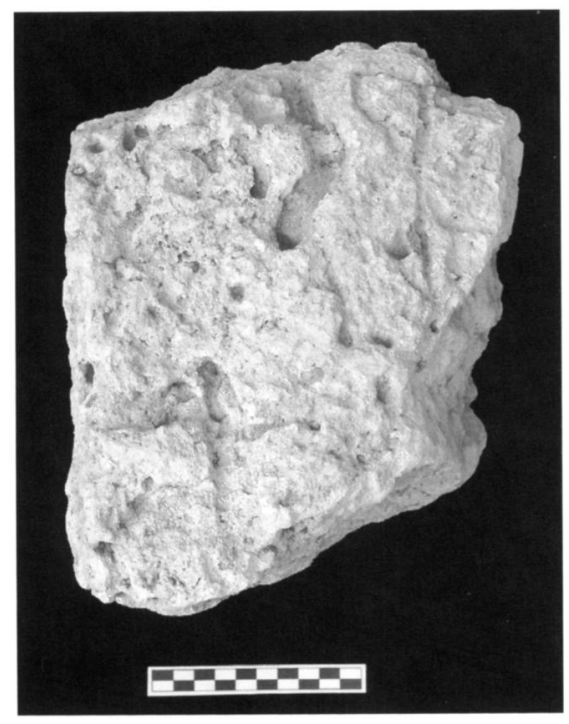

32 Open vessel

NVAP 10016001. EU 21, SU 10016 N241-243 E693-694, N241 E693. P.H. $2.5 \mathrm{~cm}$.

Fragmentary body. Possibly from the same vessel as 16 based on fabric and decoration. Fine ware, core $7.5 \mathrm{YR} 7 / 4$ pink, surface $10 \mathrm{YR} 8 / 3$ very pale brown, paint 2.5YR 5/8 red. Curve-stemmed spiral? (FM 49) over horizontal band.
Figure 16. Female figurine 30.

Scale 1:2. Drawing N. Wright and K. E. Leaman
Figure 17. Block fragment 31. Photo J. C. Wright 


\section{TEST TRENCHES}

Testing the area up the ravine from the tomb proved difficult, because it was necessary to clear thick underbrush from the trees and then to remove the dense, ca. $30-50 \mathrm{~cm}$ thick pine-tag and humus layer that overlay the caliche. This undertaking was complicated by the root system of the pines, which runs across and into the surface of the friable caliche to create a network holding the soil over it. This work was also potentially damaging to the pines because it exposed the roots and dried them out. North and west of the tomb, trenches were placed parallel to the slope. In the immediate area of the tomb, these were formal trenches $1 \mathrm{~m}$ wide and 6-10 $\mathrm{m}$ long (EU 22-24; Fig. 4). As we searched over a wider area, it was impractical to lay out each trench with the total station, and instead work crews cut running trenches about $0.30 \mathrm{~m}$ wide. These exposed the hardpan surface of the caliche, conglomerate, or sterile marl. Over $6,000 \mathrm{~m}^{2}$ were preliminarily explored in this manner.

During the 2002 season, Michael Boyd from the Fitch Laboratory of the British School of Archaeology tested the applicability of using a resistivity meter and a Fluxgate gradiometer to prospect for tombs in the area. In none of the areas in which we had permission to work in 2002-within the forested land and in the adjacent fields-was he able to employ these devices with success. The steepness of the slope, overburden due to recently made agricultural terraces, and nature of the surface deposits frustrated our attempts to located subsurface features. In 2003, the goal of research was to test for evidence of chamber tombs on both sides of the ravine at Barnavos. On the west side, where the property in which the tomb is located had been purchased, four long trenches (EU 25-28; Fig. 4) were excavated. On the east side, the entire field east of the agricultural road was tested by Donald Barber of Bryn Mawr College using ground-penetrating radar (GPR) (Fig. 18) and by two test trenches (EU 29; Figs. 4, 18, 19). None of the tests revealed any evidence of archaeological remains.

The tests in EU 25-27 were made using a mechanical backhoe (Fig. 20). Each cut was carefully inspected and photographed. We cut through the topsoil and into the underlying sterile marl base to be certain that we had inspected below any area of possible human disturbance. No artifacts were found in any of the three trenches. After this work, each trench was backfilled. In the east field, we secured written permission from the landowners, Vassilis and Athanasios Skazas, to undertake tests. This permission was restricted to the fallow fields that lie below an olive grove on the west-facing slope (Fig. 18). In the field we established a grid of $10 \times 10 \mathrm{~m}$ that ran perpendicular to the slope. This grid was used for the test lines for GPR subsurface prospection. In order to establish a baseline for interpreting the data, Barber ran several tests where the underlying rock strata were evident. A total of 15 transects were taken with the GPR (Fig. 18). Most of them confirmed the expected profile of the underlying soil and bedrock. Several, however, showed anomalies that seemed worthwhile to test by excavation. After the GPR work was complete, we established a north-south grid and cut two trenches into the hard palaeosol that caps the marl in the area (EU 29; Fig. 19). No artifacts and no trace of any disturbance other than the marks of a deep plow were found. 

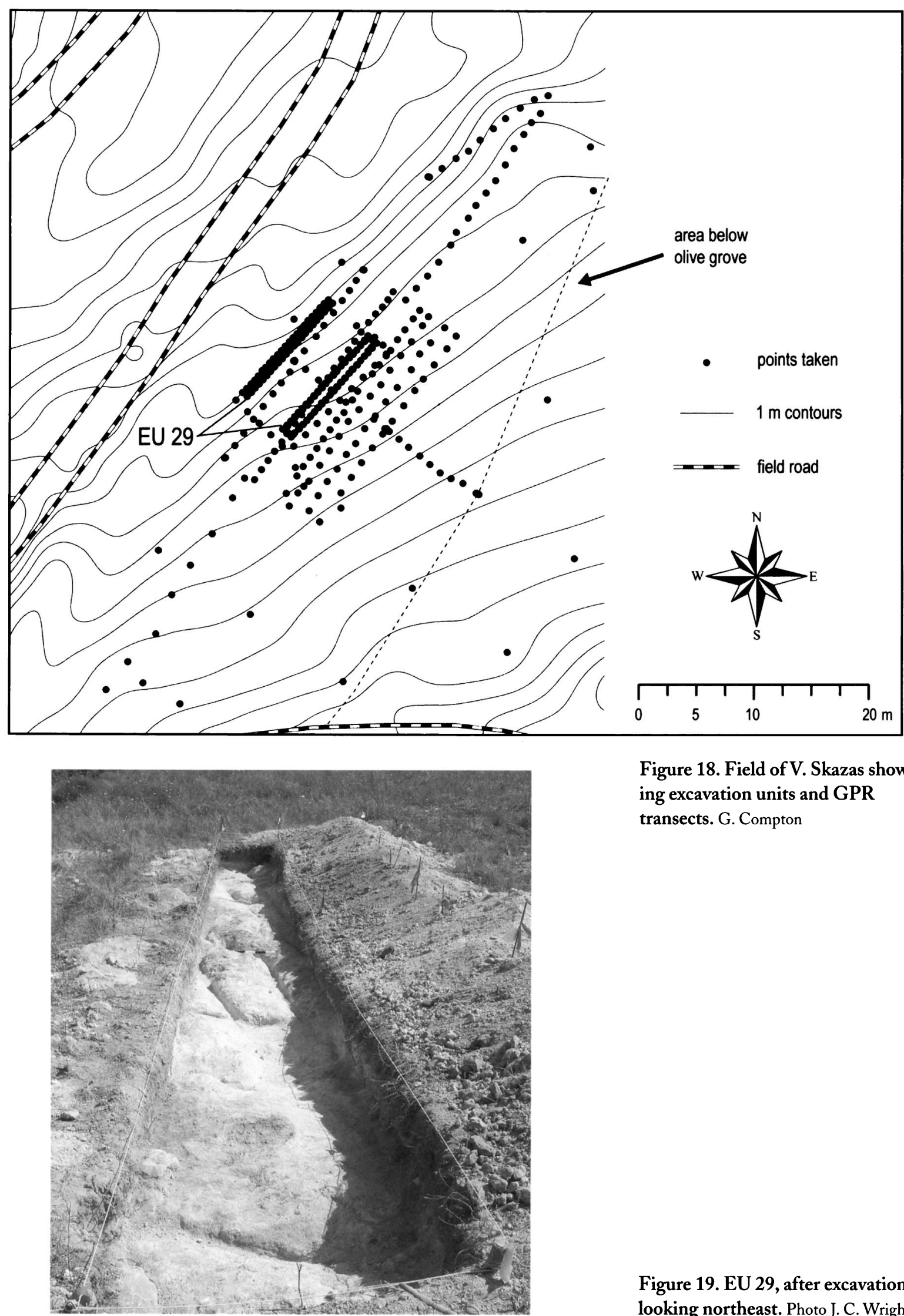

Figure 18. Field of V. Skazas showing excavation units and GPR transects. G. Compton

Figure 19. EU 29, after excavation, looking northeast. Photo J. C. Wright 
Figure 20. Test trench 25 excavated with a backhoe, looking northnorthwest. Photo J. C. Wright

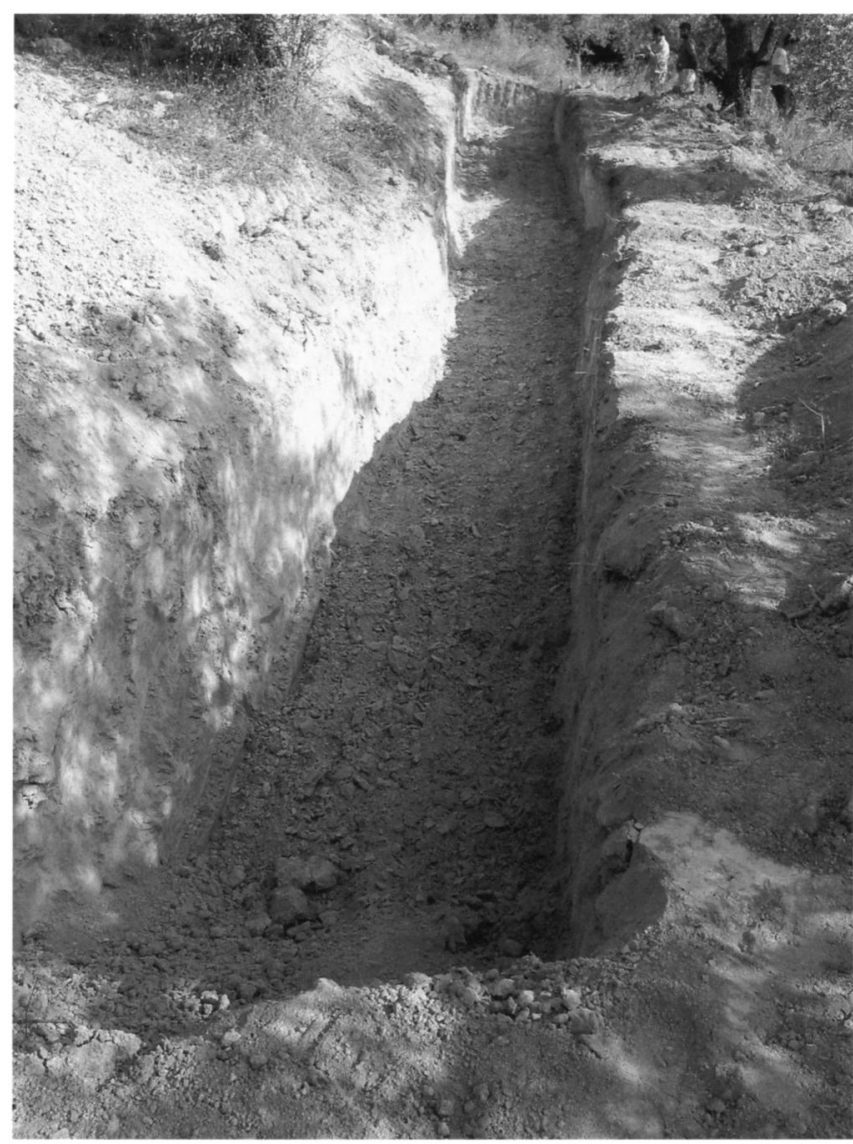

Excavation of the test trenches laid out north of EU 21 also disclosed no evidence of tombs (Fig. 4). The caliche that predominated in the area around the tomb was not present in these test trenches. It is clear from the deep plow lines in the eastern side of EU 21 that, since World War II, bulldozing to create an agricultural terrace on the property to the north had removed any caliche that capped the marl. EU 22 disclosed only sterile marl. EU 23 was located on the upper surface of an agricultural terrace and contained some evidence of Roman activity (35), all of which lay atop otherwise undisturbed soil. EU 24 is set only a meter to the west of EU 23 and is directly below a terrace scarp into which tomb robbers had dug a slit trench running north-south; this test disclosed only the sloping marl rising to the next agricultural terrace. Atop that terrace the tomb robbers had also dug a $1-\mathrm{m}$-wide hole about $1.5 \mathrm{~m}$ deep through the caliche before abandoning it.

\section{Finds from the Test Trenches and Surface}

Beyond the immediate area of the disturbed tomb, surface finds indicate activity during the Roman period. An obsidian projectile point (33) found on the surface by Compton is unrelated to the tomb.

33 Projectile point

Fig. 21

NVAP 10001001. SU 10001. L. 2.6, W. 1.4, Th. $0.6 \mathrm{~cm}$.

Intact. Triangular, tanged with hollow point, retouched. Obsidian. 


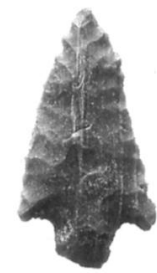

33

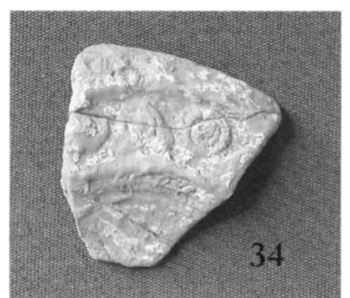

34 Lamp

NVAP 10001002. EU 21, SU 10001., P.H. 0.9, Diam. rim 6.5, Diam. disk $4 \mathrm{~cm}$.

Fragmentary rim and disk, $10 \%$ rim circumference. Fine ware, core and surface 5YR 6/6 reddish yellow. Molded relief of ca. 1-cm-wide band of concentric circles in a row on rim, 7-mm-wide band of "fishbone" pattern at edge of disk.

Roman.

35 Jar

Fig. 21

NVAP 10052001. EU 23, SU 10052 N252-253 E689-690. P.H. 3, est. Diam. $\operatorname{rim} 14 \mathrm{~cm}$.

Fragmentary rim. Rolled rim with groove on top, offset neck. Medium coarse ware, core $2.5 \mathrm{YR} 4 / 6$ red, surface N 5/0 dark gray, many white stone inclusions, $<3 \mathrm{~mm}$. Unpainted.

Roman.

36 Coin

NVAP 10053001. EU 23, SU 10053 N255 E689. Diam. $0.0831 \mathrm{~cm}$.

Intact. Minimus. Bronze.

Cf. Knapp and Mac Isaac 2005, p. 211, no. 2475, pl. 30:b.

Justin II, A.D. 565-578. ${ }^{14}$

\section{DISCUSSION}

The robbed chamber tomb at Barnavos dates to LH IIIA2, with much of the pottery datable to late in that phase. One object (16) from the dromos may be placed early in that period, while one object from the chamber (6) may be as late as LH IIIB1. As will be presented below, there is good evidence the tomb was opened multiple times, so the prospect of it having been used over perhaps a couple of generations should be entertained.

The tomb is situated about $1,300 \mathrm{~m}$ to the west-southwest of Tsoungiza. It is the first evidence of burial to appear in the valley that can be associated with the LH settlement. Its location on the lower slope of a ravine that carried runoff water from the slopes of Daouli is suitable for the establishment of a cemetery comparable to others, notably at Mycenae, where ravines are often the locations of chamber tomb cemeteries. ${ }^{15} \mathrm{After}$ extensive searching of the area around the tomb, we concluded, however, that there was little probability of there being any other tombs in the immediate vicinity of this one. The only area we considered likely, but were unable to test, was the east-facing slope to the east of the ravine. This slope

14. The authors thank Robert C. Knapp for this identification.

15. Cavanagh and Mee 1990; Shelton 1993.
Figure 21. Projectile point 33, lamp

34, and jar 35. Scale 1:1 (33); 2:3 (34); 1:3

(35). Photos J. C. Wright $(33,34)$, drawing

N. Wright and K. E. Leaman (35) 
faces the settlement on Tsoungiza. There is no a priori reason to believe that tombs were located there, but some anomalies on the ground surface attracted our interest. Unfortunately, the conditions of the written permission of the landowners prevented us from sinking trenches in this area.

Why there is only one tomb is unclear. Elsewhere single tombs are known, but it is not always easy to ascertain if a thorough search was made for other tombs in the area, especially when the tombs were salvaged as a result of chance discovery. ${ }^{16}$ For example, at Mycenae, where many chamber tomb cemeteries are scattered around the citadel, single tombs are not found. Usually there is another one within at least $100-300 \mathrm{~m} \cdot{ }^{17}$ Elsewhere in our immediate region (at Zygouries and Aidonia), no single tombs were found ${ }^{18}$ This is also largely true throughout the Argolid and elsewhere in the Peloponnese. ${ }^{19}$ It seems unlikely that the ground surface and underlying Neogene marl were judged unsuitable for chamber tombs since, for example at Mycenae, all kinds of sedimentary deposits were dug into. ${ }^{20}$ Moreover, the hard palaeosol that had developed in this area was thick enough (before being effaced by modern deep plowing) to provide a thick and durable roof over the marl into which the chamber was excavated. ${ }^{21}$ Perhaps a single family chose this area for burial and subsequently no other members of this family or lineage remained or chose to bury here.

During the summer of 2002, a second burial place was identified in the region. It lies about $1,100 \mathrm{~m}$ to the west of Tsoungiza, on the eastern slopes of the high hills that rise to Mt. Prophitis Elias (ancient Mt. Trikaranon) at Ayia Sotira (Fig. 1). ${ }^{22}$ The presence of a spring has been reported nearby. ${ }^{23}$ In 2002, a salvage excavation was conducted in one of the chamber tombs situated in the olive grove of Panayiotis Tombros. The work was carried out under the direction of Pappi for the 4th Ephorate of Prehistoric and Classical Antiquities during July and August 2002. The tomb dates to $\mathrm{LH}$ IIIB1. Two other tombs had been robbed and there are signs in the olive grove that indicate the probable position of several other tombs, so plans are underway to conduct systematic excavation of the entire cemetery. In view of this discovery, it seems likely that Tsoungiza had multiple locations for different residential or family groups to bury their dead, as hypothesized earlier by Dabney. ${ }^{24}$

16. For example, the single tomb from near the railway station of $\mathrm{New}$ Corinth recorded by Vanderpool (1954, p. 232), or one from Krines, along the railway line west of Corinth reported by Krystalli-Votsi (1969), or another near Phyktia at Boliari reported by Protonotariou-Deilaki (1966). Elsewhere in this region, extensive cemeteries were explored at Kato Almyri (Banaka-Dimaki 1988) and Perachora (Hatzipoulou 1988).

17. Shelton 2003, p. 35 , and see, for example, maps $2,3,6$, and 7; map 10 (H3:02a, p. 60), however, shows one tomb discovered through survey but thought to be "possibly one of a line of tombs," while tombs spaced ca. $300 \mathrm{~m}$ apart are known from the region of Tserania, Gouves, and Ayia Paraskevi (Shelton 2003, map 11, and p. 60, G4:07, G4:11).

18. Zygouries: Blegen 1928, pp. 5765; Aidonia: Krystalli-Votsi 1986;

Demakopoulou 1996.

19. Cavanagh and Mee 1998, pp. 83-88; Boyd (2002) does not record any single chamber tombs in his regions of study (Lakonia, Messenia, and Elis).
20. Shelton 2003, p. 35.

21. Blegen (1937, pp. 229-231) observes that over 50 tombs were cut into the rock or marl that lay beneath ledges of conglomerate that formed the roof over the chamber.

22. Late Helladic pottery was identified at Ayia Sotira (site 602) by the NVAP survey (Cherry, Davis, and Mantzourani 1996, s.v. site 602). 23. Wright et al. 1990, p. 589; Cherry, Davis, and Mantzourani 1996, s.v. site 603; Dabney 1999, p. 175. 24. Dabney 1999, pp. 174-175. 


\section{HUMAN BONE STUDY}

Preparation for the recovery and analysis of human bones began in August 2001 with the writing of a proposal for the work to be done, assembling a team of scientists and experienced postgraduate students, coordinating specialized support from the Wiener Laboratory of the American School of Classical Studies at Athens (ASCSA), and purchasing tools and basic osteological supplies. ${ }^{25}$ Special recording forms were drawn up in anticipation of discovering articulated as well as disarticulated burials. In this manner the bioarchaeological aims of the project were put foremost in the planning, and shaped the overall goals and procedures of the project.

Laboratory work took place in the conservation room at the Nemea Museum. This involved careful soft brushing and cleaning of the skeletal material with tap or deionized water, drying it indoors, labeling the bones with permanent black ink, and recording and entering the data in a database.

\section{MeTHODOLOGY}

Upon discovery of the extent of the disturbance of the skeletal remains caused by the plundering of the tomb, adjustments were made in the methods for the recovery and analysis of the bone material. The commingled human bone fragments recovered during excavation represent three different kinds of remains and episodes of disturbance. First are burials that may have been moved within the chamber after primary burial. Second are remains thoroughly disturbed by looting, which created the third and most damaged category, namely those remains degraded by environmental factors during exposure to the elements.

Consequently, the most difficult osteological task was to match different fragments of the same skeletal elements scattered in the dump and throughout the chamber. In contrast to the evidence from pottery, no fragments from the same bone were found inside the chamber and outside in the dumped soil (Figs. 22-24). Different bone fragments were dispersed in neighboring SMUs of the same stratigraphic unit. The broken edges of the fragmented bone material were not fresh and probably indicate the degree of trampling and shoveling by the tomb robbers.

These factors limited osteological analysis to the estimation of the minimum number of individuals (MNI), aging/sexing, calculation of metrics, and recording of the postdepositional taphonomic processes that affected the human bone remains after burial. ${ }^{26}$ The MNI was based on the identified skeletal elements counted in terms of standard anatomical units set for disarticulated skeletal assemblages and reckoned according to which side of the skeleton they belonged.$^{27}$ Given the poor preservation of the skeletal remains, estimation of age at death was possible only for the two broad categories of adults and subadults. The identified skeletal elements were aged according to epiphyseal completion, tooth development, and bone morphology. ${ }^{28}$ Because of the overall lack of the necessary anatomical pelvic, cranial, or long bone points, no secure identification of sex could be made. Finally, metrics and taphonomy were based on the standards described by Buikstra and Ubelaker. ${ }^{29}$
25. Triantaphyllou warmly thanks Anastasia Papathanasiou, Ephorate of Palaeoanthropology and Speleology, and Kostas Moraïtis, Department of Forensic Anthropology, University of Athens, who discussed with her matters of retrieving, recording, and analyzing human bone material.

26. Boddington, Garland, and Janaway 1987; Waldron 1994; Nawrocki 1995; Littleton 2000.

27. Buikstra and Ubelaker 1994, p. 9, attachment 2; Lyman 1994.

28. Ubelaker 1978; Brothwell 1981; Steele and Bramblett 1998; White 2000.

29. Buikstra and Ubelaker 1994, pp. 69-84, 95-106. 


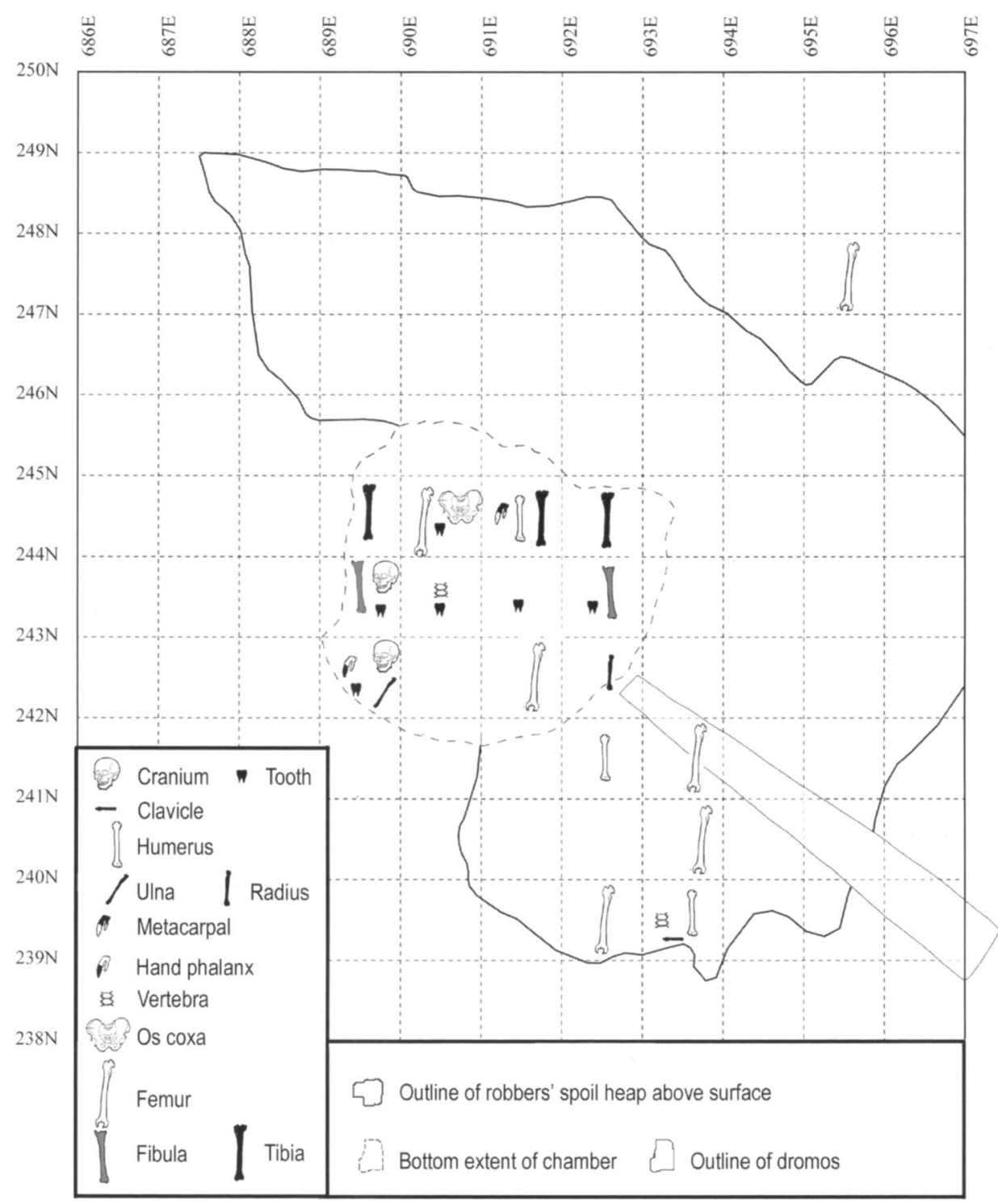

Figure 22. Distribution of identified human skeletal material. G. Compton and J. C. Wright

30. Of the 304 catalogued bone fragments, 220 were excavated and collected according to the SMU system. Additionally, 29 bone fragments were collected from the surface of the dump by the Head Guard, M. Nikitakou, and Wright during their visit to the site in July 2001.

\section{RESULTS}

All human bone material from the robbed tomb was dispersed within two main locations: the dump (SU 10002, 10003, 10004, 10011, and 10012) and the chamber (SU 10022 and 10023). The dromos provided no evidence of primary or secondary burial activity. We were able to distinguish some areas of the dump and chamber with a greater density of human bone than others (see below).

A total of 304 human bone fragments were catalogued, and of these, 135 bone fragments were recovered from the robbers' dump, while the remaining 169 came from the chamber. ${ }^{30}$ The human bone material from EU 21 (Fig. 25) is characterized by a predominance of long bone fragments (mainly femurs and tibias). Small bones are very poorly represented (one hand phalanx, one metacarpal, and two vertebral fragments); of flat bones, only one pelvic fragment was found; finally, there are a few cranial fragments and 13 teeth (12 permanent and one deciduous). Of the 304 


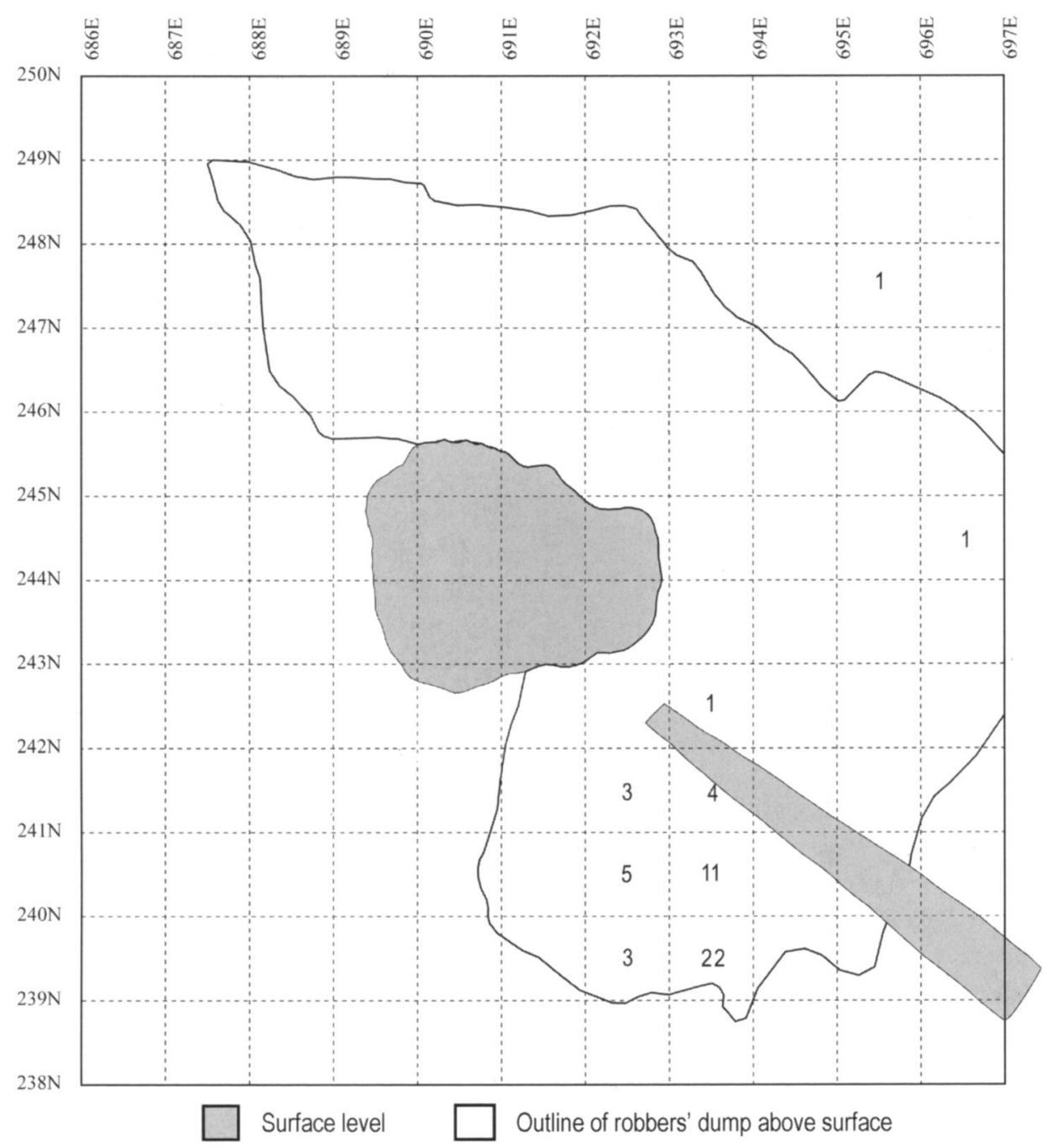

catalogued fragments, 204 were unidentifiable. Figures 23 and 24 illustrate the total distribution of catalogued bone fragments excavated by the SMU system.

Bone representation has been highly affected by disturbance during looting, root development, and by weathering, which exposed the bone to sunlight, water, and wind. ${ }^{31}$ The preservation of long bones and the near total loss of small/flat bones, cranial bones, and teeth reveal the powerful effects of exposure to the elements-a situation exacerbated by the steep slope, as the lighter bone fragments eroded from the surface, leaving only the heavy and large long bone remains. Strongly supporting this observation is the fact that, except for one vertebral fragment and one clavicle, the dumped soil outside the tomb yielded only long bone fragments (Fig. 22). With regard to taphonomy, this exposure destroyed most diagnostic elements, including trabecular bone such as joints and bone epiphyses, and flaking, staining, and discoloration of the periosteum (the bone's outer surface). There is, however, one case of greenish discoloration on a left femoral midshaft fragment belonging to an adult (Fig. 26), indicating that the femur was associated with a bronze artifact, presumably the razor (5).
Figure 23. Distribution of human skeletal material in the dump $(n=51)$. G. Compton and J. C. Wright
31. Littleton 2000, p. 15. 


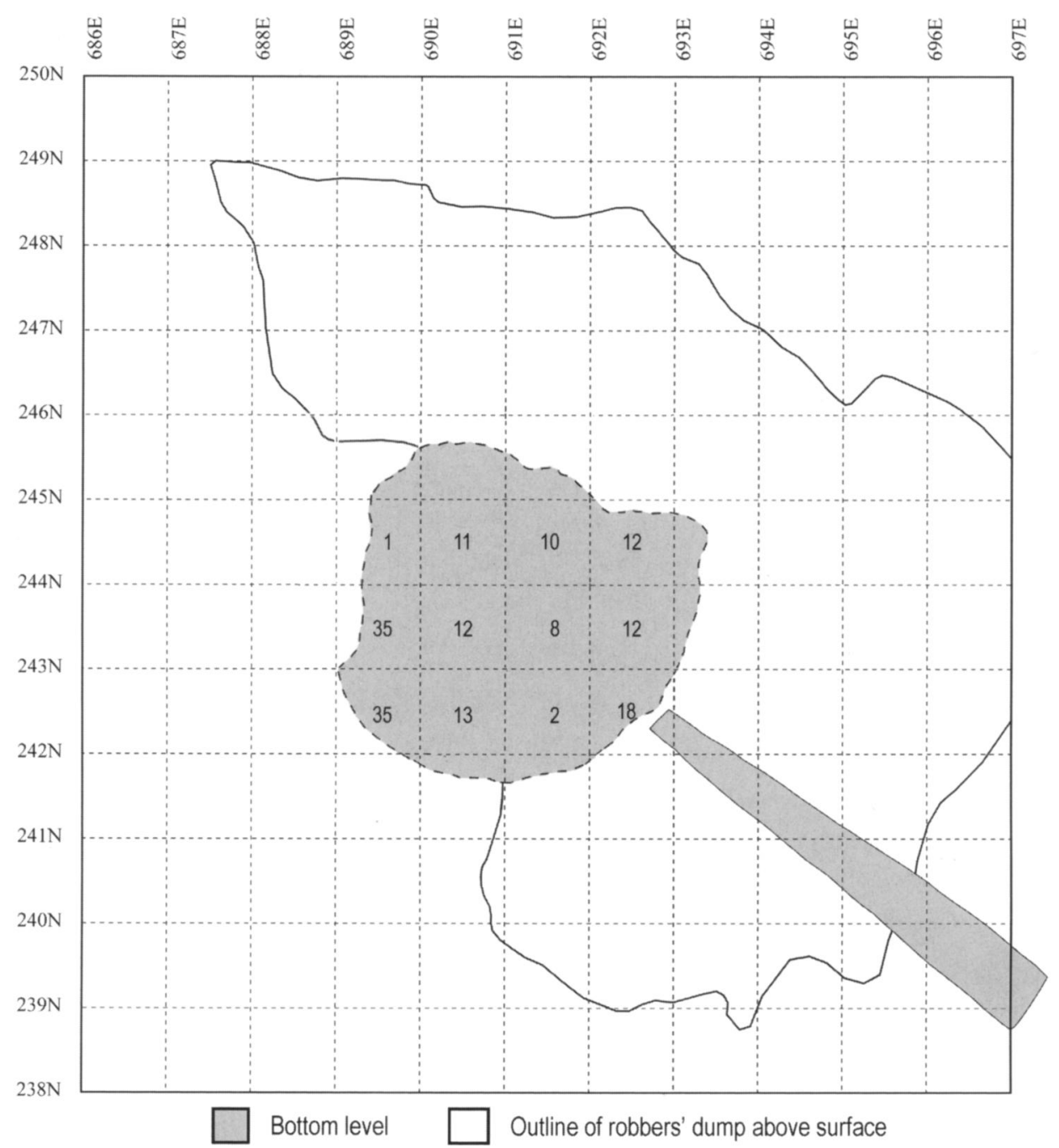

Figure 24. Distribution of human skeletal material in the chamber $(n=169)$. G. Compton and J. C. Wright
Study of the distribution of bone fragments in the area (Figs. 22-24) may help us to reconstruct the probable original location of the burials and to understand the process of the looting. As noted above, shoveling by the robbers of the soil from the chamber was primarily directed to the east-southeast area outside the tomb. We assume that areas within the chamber that contained cranial fragments, teeth, and small or flat bones better represent the skeletons than locations where only long bones or unidentified bone material was present, because they were most susceptible to being trampled as the robbers cleaned out the chamber in the dark of night. It seems possible that those areas inside the chamber might approximate the in situ locations of the burials. These are in the southwest (SMU 242/689-690), west (SMU 243/689-690), and the northeast (SMU 244/691-692) parts of the chamber, and it does not seem accidental that the two burial pits are located within these areas (see Figs. 9, 10, above). This observation, however, is compromised by the study of the bone remains of a child. Since the bone fragments of children are easily recognized, examination of their distribution shows how thoroughly the robbers disturbed the chamber. Although child bones and teeth are 

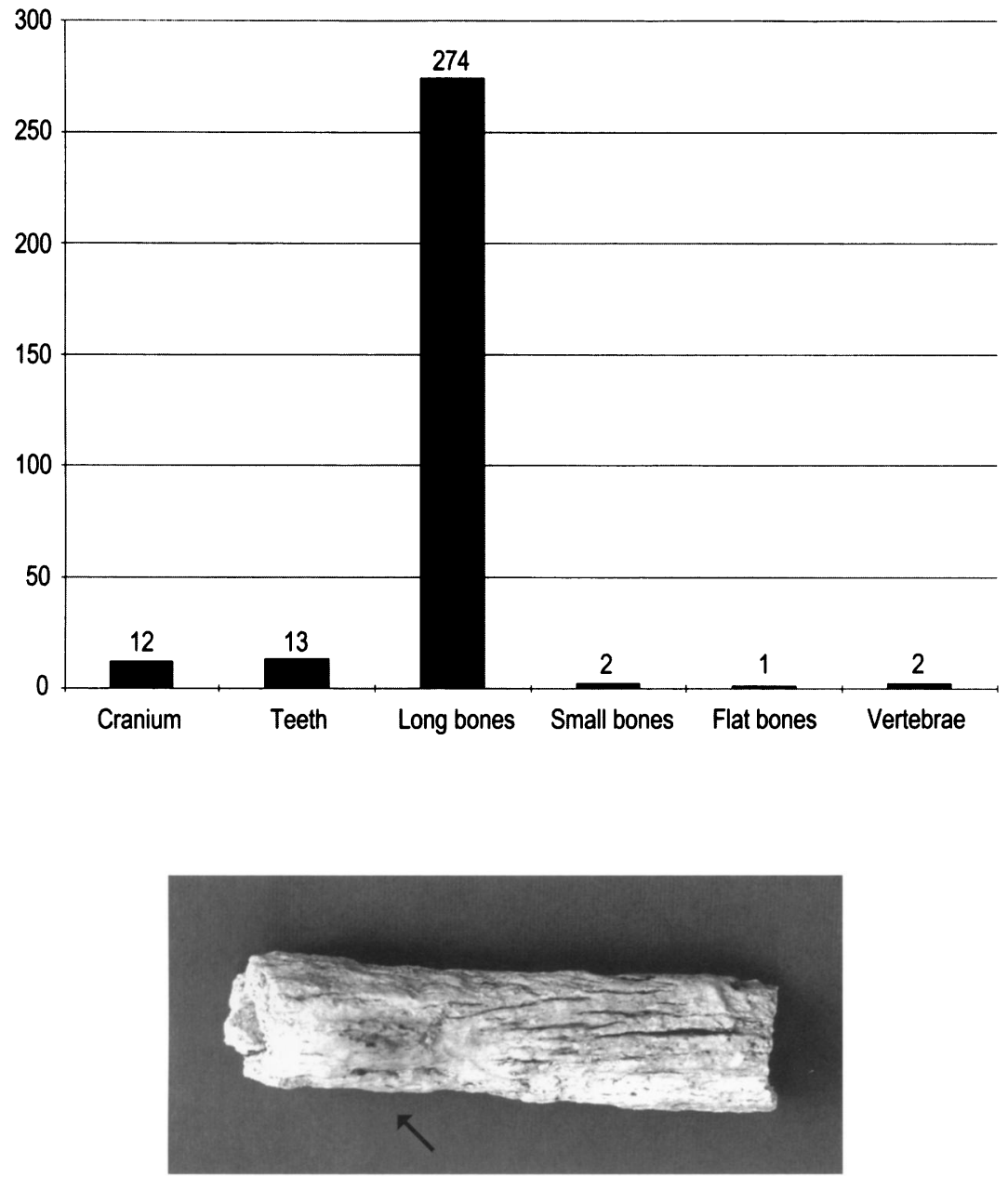

limited to the southern area where one of the burial pits is located, they are dispersed mostly in SMU 242/689-690, 692, SMU 243/689-690, 692, and at a significantly lower frequency in SMU 244/691-692. In general, however, the pattern of bone distribution from the dump and from the chamber is similar to that of the pattern-painted pottery. This strengthens the hypothesis that they were shoveled out together when the tomb was robbed.

On the basis of this information, it is possible to estimate that the minimum number of individuals buried in the tomb was four, with a weak possibility of a fifth adult. Three were adults and one a child nine to ten years old, according to tooth development and measurements of long bone lengths. Although bone morphology is unclear in the long bone fragments because of weathering and damage resulting from the looting of the chamber, it may be ventured that the tomb contained at least one man and one woman. Preservation affected also metrics, which could only be estimated for long bone fragments and teeth.

Only minimal evidence of pathology was observable - all of dental disease. Lines of enamel hypoplasia on three out of five of the child's permanent teeth demonstrate that he or she probably suffered at least one stress episode during infancy. ${ }^{32}$ There is also evidence of two carious anterior teeth, an
Figure 25. Number of catalogued human bones by skeletal element $(\mathrm{n}=304)$. S. Triantaphyllou

Figure 26. Adult bone fragment with discoloration from contact with bronze. Photo S. Triantaphyllou

32. Enamel hypoplasia refers to the surface dental effects on tooth enamel resulting from the disturbance of enamel formation. It represents episodic disruptions to matrix secretion throughout the growing dentition. See Goodman, Armelagos, and Rose 1980, p. 515; Goodman and Armelagos 1985, pp. 479-480; Hillson 1996, pp. 165166. 
upper second incisor and a canine, respectively; the position of the carious lesions is very uncommon since caries usually affect posterior dentition. Given a minimum of four individuals buried in the tomb, their estimated ages, and the possibility that both sexes are represented, a hypothesis that the burial group was a family seems reasonable. ${ }^{33}$

\section{GEOLOGICAL STUDY}

Archaeologists have sometimes observed stratigraphy in chamber tombs, both in the chambers where successive depositions were made, ${ }^{34}$ and in the dromoi, where successive strata record periodic openings and closings. ${ }^{35}$ Such strata in dromoi are hard to detect with the naked eye because the fill of each episode is essentially the same soil as the previous fill and it is presumably also the same soil that came from the original excavation of the tomb. Hence, when strata have been discovered, it is often organic refuse or small stones that define the interface between different layers. ${ }^{36}$

In this report, the study of the stratigraphy and formation processes of the sediment fill of the dromos is presented on the basis of micromorphological investigation, although an attempt was made to excavate the dromos stratigraphically (Fig. 27). A cross-section and a part of a longitudinal section of the sediment fill was preserved during excavation in order to expose the fill for visual examination and for sampling appropriate areas for laboratory analysis of the sediments (Figs. 27,28). As described above, the tomb is dug into Neogene marls covered by a calcareous palaeosol (caliche). Recent colluvial and dark forest topsoil overlie the caliche, but in places the latter is missing due to recent agricultural activities. It seems that the Mycenaeans who dug the tomb took advantage of the hard calcareous soil because it offered an excellent rigid roof for protecting a chamber dug beneath it. ${ }^{37}$

\section{Field Observations}

In the field, different sedimentary layers are normally defined using criteria such as color variations, texture and stoniness, structure, and geometry of the boundaries. ${ }^{38}$ In this case, however, the sediment fill is primarily

33. Cavanagh and Mee (1998, pp. 71-78) discuss the evidence for chamber tombs being family tombs; Wells (1990, pp. 138-139), however, is skeptical that this is universally the case.

34. Wace 1932, p. 131; Blegen 1937, pp. 231-232, 250, see tombs II, XII, XV-XVII, XXV-XXXVII, XLIII, XLIV, and XLIX.

35. At Mycenae, Wace (1932, pp. 127-128, 144-145) observed that dromoi were frequently opened and refilled, but he based his observation on his assessment of the pottery and the location of burials higher up in the dromos; at Prosymna, Blegen (1937, p. 236) claimed there was "no proper stratification" in the dromoi because they had been repeatedly opened and the fill within was inextricably mixed. In contrast, the Swedes were very successful in recognizing stratigraphy in the dromoi of chamber tombs, e.g., at Dendra, where Persson (1931, pp. 82, 87, 93; 1942, pp. 31-33, 37, 51-53, 59) recorded stratigraphy, especially in the drawn sections, of tombs 1-3 and 7-10, and at Asine, where Frödin observed and drew in section strata in tombs I,1; I,2; and I,7 (Frödin and Persson 1938, pp. $158,162-163,165,183-184)$. See also Åström 1977, pp. 68-69, 107, noting stratigraphy in the dromoi of tombs 13 and 14 at Dendra, and discussion in Boyd 2002, pp. 63-64.

36. See discussion of this phenomenon in Cavanagh 1978; Wells 1990, pp. 135-138; and Cavanagh and Mee 1998, p. 76.

37. See n. 21, above.

38. Courty, Goldberg, and Macphail 1989. 

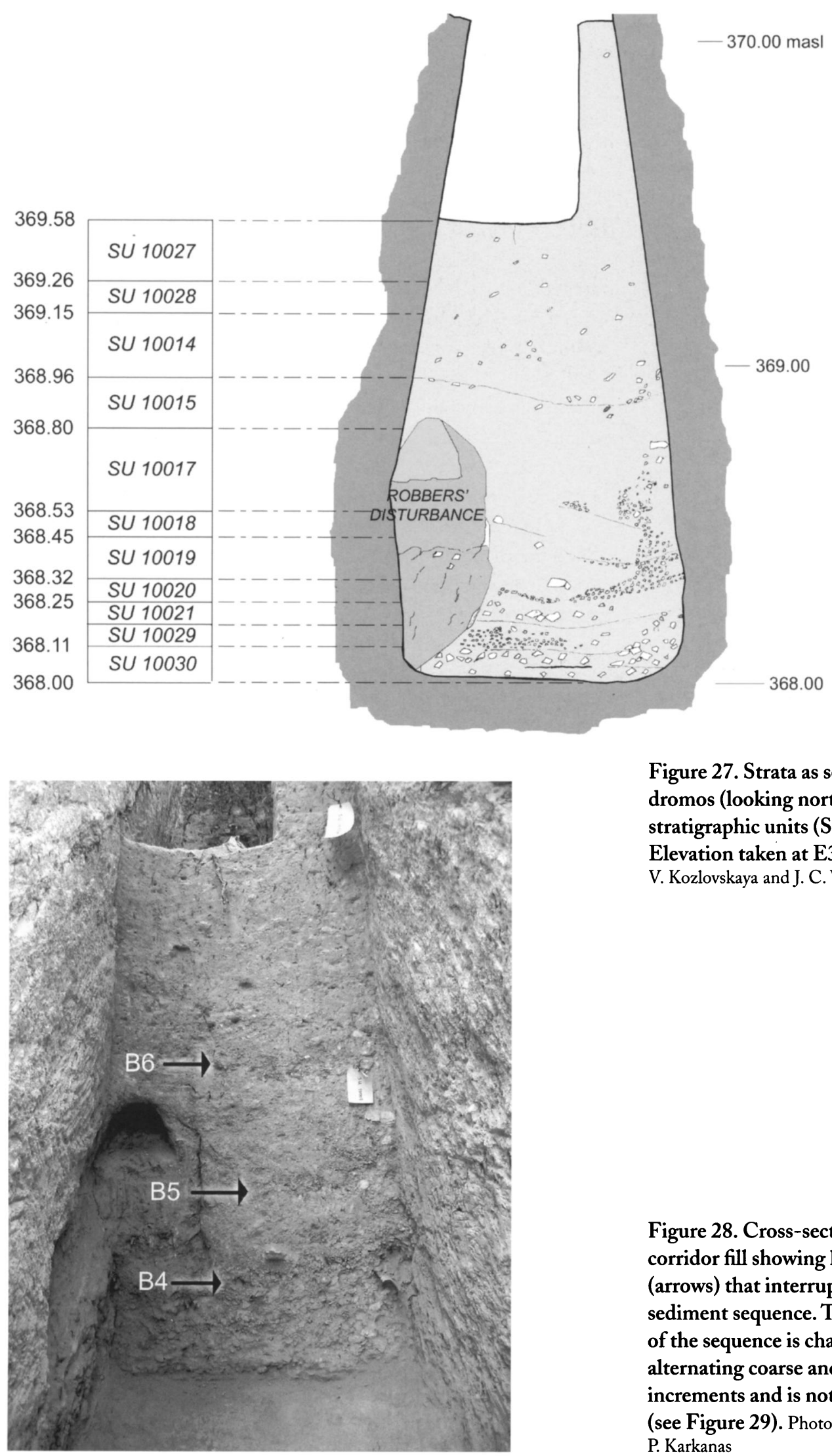

Figure 27. Strata as seen in balk of dromos (looking northwest) and stratigraphic units (SU) as excavated. Elevation taken at E369.65.

V. Kozlovskaya and J. C. Wright

Figure 28. Cross-section of entrance corridor fill showing linear features (arrows) that interrupt the massive sediment sequence. The lower part of the sequence is characterized by alternating coarse and fine gravel increments and is not homogeneous (see Figure 29). Photo J. C. Wright and P. Karkanas 


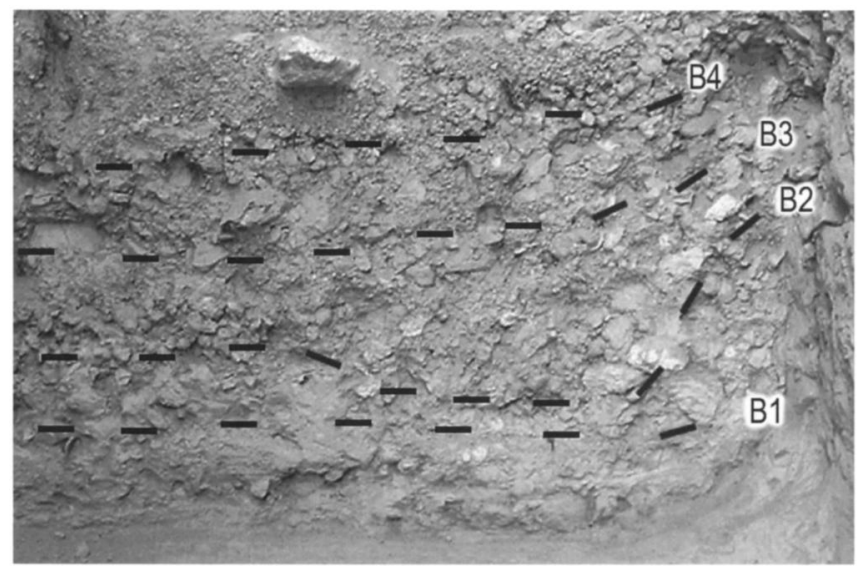

Figure 29 (above). Lower part of the entrance corridor fill showing the first four boundaries between alternating coarse and fine sediment increments. Vertical dimension $0.90 \mathrm{~m}$. Photo J. C. Wright and P. Karkanas

Figure 30 (right). Columns cut for sampling, with intact and oriented beds of sediment (lines indicate slope of fills). Some of the layer boundaries are also marked on the longitudinal section of the entrance corridor fill. Note the inclination of the boundaries downward toward the chamber. Photo J. C. Wright and P. Karkanas

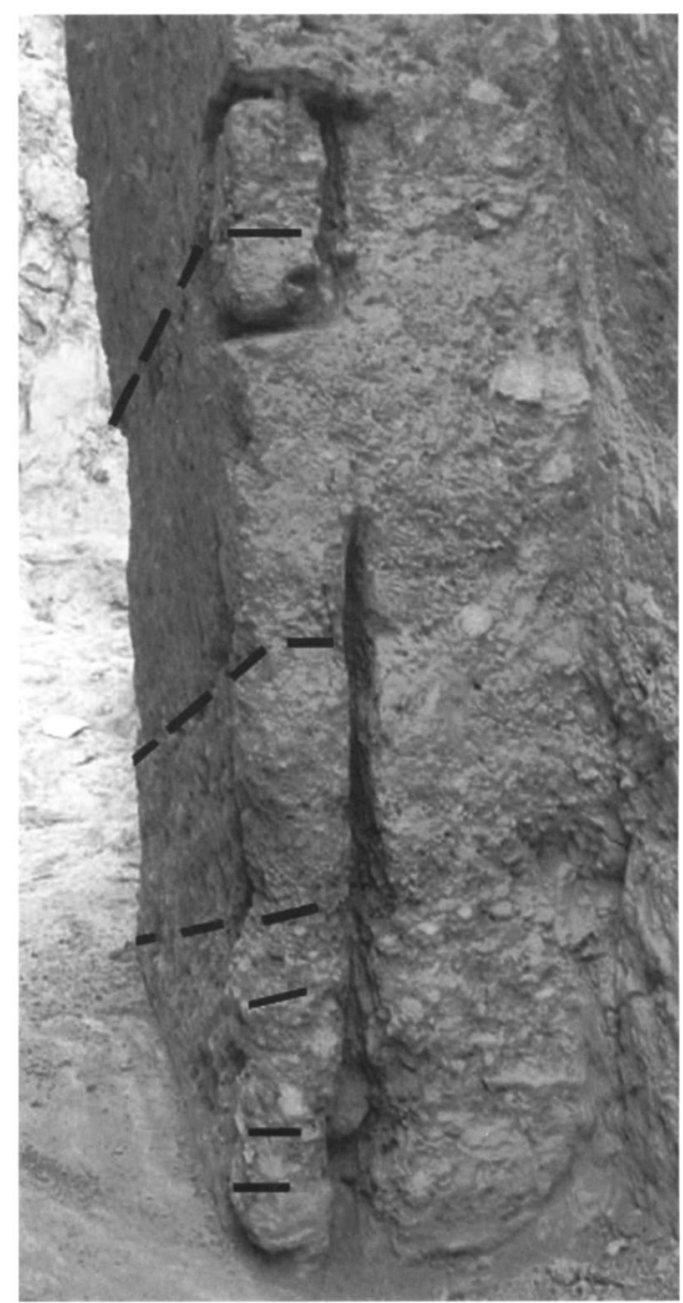

homogeneous in appearance, and only a few almost-linear features interrupt the massive texture of the sediment fill (Fig. 28). Thus, there are no discrete characteristics that help us to separate the fill into different layers; instead, there are only boundaries between similarly appearing bodies of sediment. We can best describe those boundaries as suture or discontinuity zones in that they are loose surfaces defined by an almost abrupt change in the grain size of the sediment clasts. In most cases, these zones consist of a linear body of gravel-sized clasts of sediment (such as a rock-line) between a relatively homogeneous mixture of clasts of different sizes. Because these zones are looser and more porous than the surrounding sediment, they are areas of weakness where, sometimes, modern roots preferentially develop.

Since there are several discontinuity zones in the lower part of the sequence that form a repeated alternation of coarse- and fine-grain increments, they can be more easily described as discrete layers (Fig. 29). However, the upper and more distant discontinuity zones are only rock-lines dividing massive sediment fill (Fig. 28). The sutures incline gently from the entrance of the corridor toward the chamber, following the inclination of the original floor of the corridor entrance (Fig. 29). Transverse to the corridor, they tilt up against its walls (Fig. 30). 


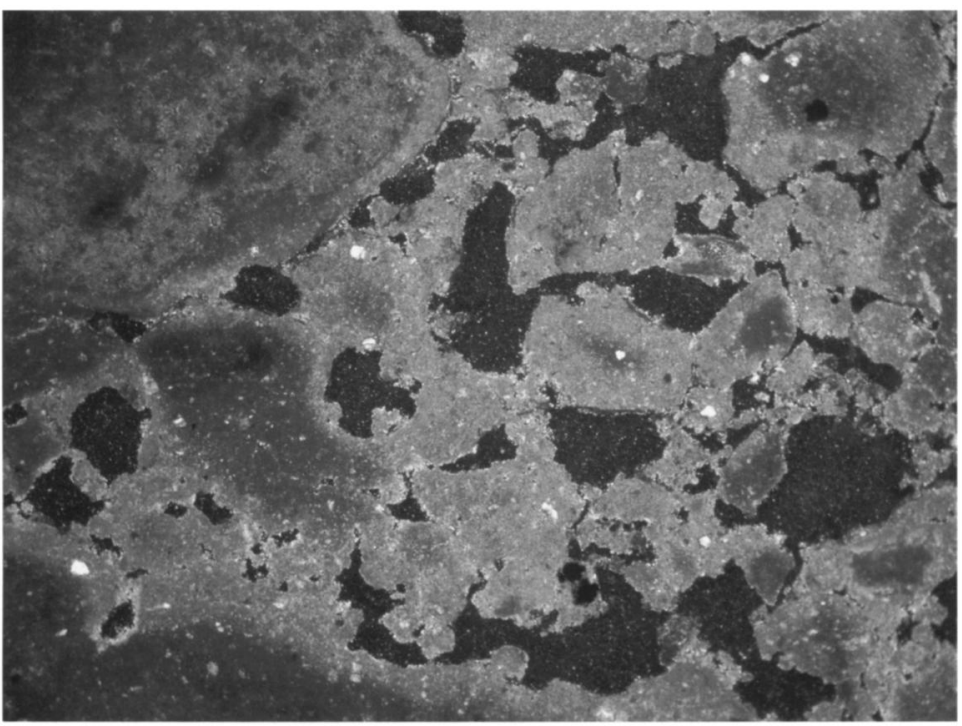

\section{MicROMORPHOLOGY}

In order to study the constituents of the sediment fill and particularly their geometric relationship, a set of samples was collected for micromorphological analysis. Micromorphology involves the study of petrographic thin sections produced from resin-impregnated, undisturbed blocks of sediment. ${ }^{39}$ Five undisturbed and oriented blocks of sediment (ca. $10 \times 10 \times$ $20 \mathrm{~cm}$ ) were removed from the preserved profiles (Fig. 30). Samples were dried and impregnated with polyester resin under vacuum. Once cured and hard, they were cut in slices, mounted on glass slides, and ground down to a thickness of 30 microns. Fifteen thin sections of $5 \mathrm{~cm}$ width and $7 \mathrm{~cm}$ length were examined under a stereoscope at a magnification of 5-40 times and under a petrographic microscope at a magnification of 50-500 times.

The majority of the sediment fill consists of marl fragments of different sizes ranging from gravel to silt (Figs. 28-33). The marl itself consists of microsparitic to sparitic calcitic clasts (grainstone) with a few quartz silt fragments, organic staining, and clay admixtures (Figs. 31-33). The sediment fill of the dromos occasionally contains a few fragments of well-crystallized calcitic aggregates and some calcareous soil fragments (caliche) from the topsoil of the site. The caliche is very characteristic in that it contains a large amount of fossilized root imprints (alveolar structures).

In general, the sediment fill is quite porous and the dominant voids are complex packing voids. In several places, however, clasts tend toward coalescence, leaving isolated vugs with smooth walls (Fig. 31). Recrystallization of the clasts is not widespread, but the shape of the voids points to a combination of postdepositional processes-namely the compaction and initial recrystallization of calcite (Figs. 31,33). Unfortunately, the nature of the sediment is not suitable to reveal details of the process of the sediment fill. Clay and argillaceous silt are not present, and thus features such as pore
Figure 31. Microphotograph of a typical fill away from the boundary zones. Packing voids (in black) are not interconnected; weak recrystallization is observed on the interface of the marl fragments; clay admixtures and organic staining are readily observed inside the marl fragments. Cross-polarized light (XPL). Horizontal dimension $3.5 \mathrm{~mm}$. Photo P. Karkanas
39. Courty, Goldberg, and Macphail 1989. 
Figure 32. Microphotograph of a boundary zone. Packing voids (with black) are interconnected. Crosspolarized light (XPL). Horizontal dimension $3.5 \mathrm{~mm}$. Photo P. Karkanas

Figure 33. Microphotograph showing platy marl fragments with recrystallized interfaces. The fragmentation pattern is due to trampling. Cross-polarized light (XPL). Horizontal dimension $3.5 \mathrm{~mm}$. Photo P. Karkanas
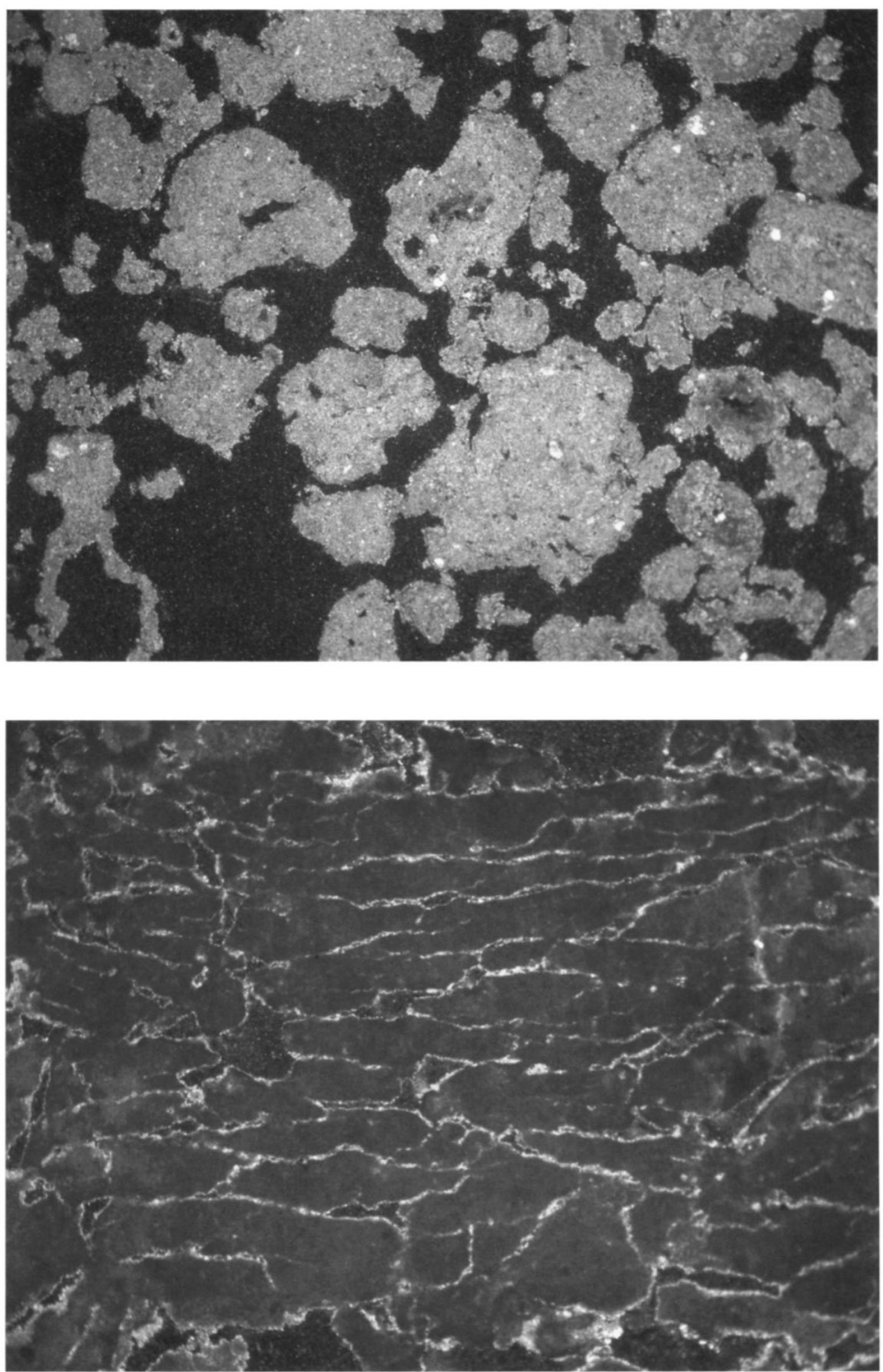

coatings cannot be readily observed. Recrystallization of calcite could be the result of postdepositional circulation of pore water.

In contrast, the discontinuity zones are very porous with open, interconnected packing voids (Figs. 32, 34-36). Normally, the space between the gravel is not filled much with finer clasts. The zones contain many large fragments of the calcareous palaeosol and some aggregates of wellcrystallized calcite. The organic material that is associated with the sutures is recent root fragments and not syndepositional organic matter. Characteristic features are the presence of platy, horizontally oriented voids, and repeated horizontal fissuring of some of the marl clasts (Fig. 33). In addition, several of the marl clasts also have platy shapes. A very interesting feature is the presence, in some cases, of a lower compacted, straight, and clear-cut microscopic surface before the accumulation of the porous gravel increment (see, e.g., Fig. 35). 

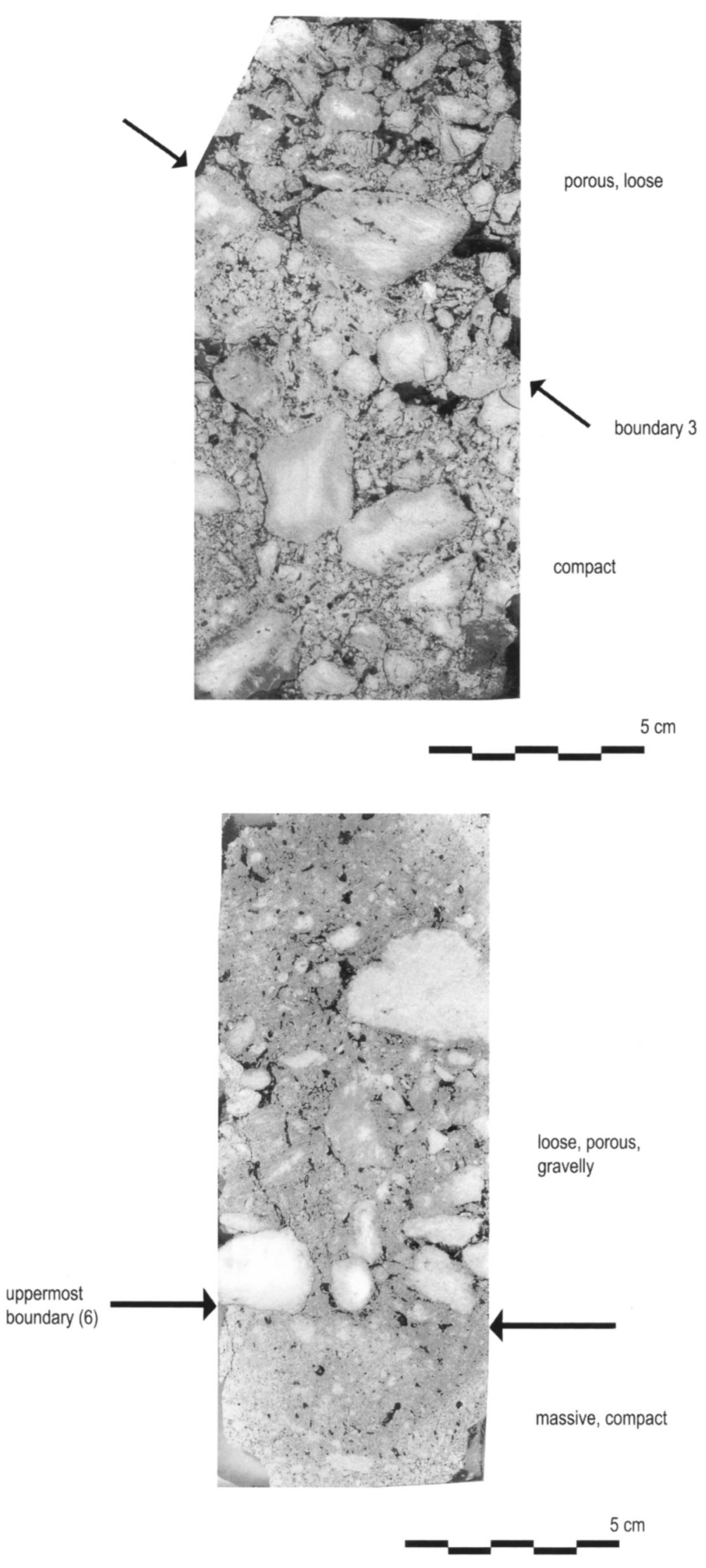

Figure 34. Macrophotograph of polished resin-impregnated slab showing boundary 3. Photo P. Karkanas
Figure 35. Macrophotograph of polished resin-impregnated slab showing boundary 6. Photo P. Karkanas 


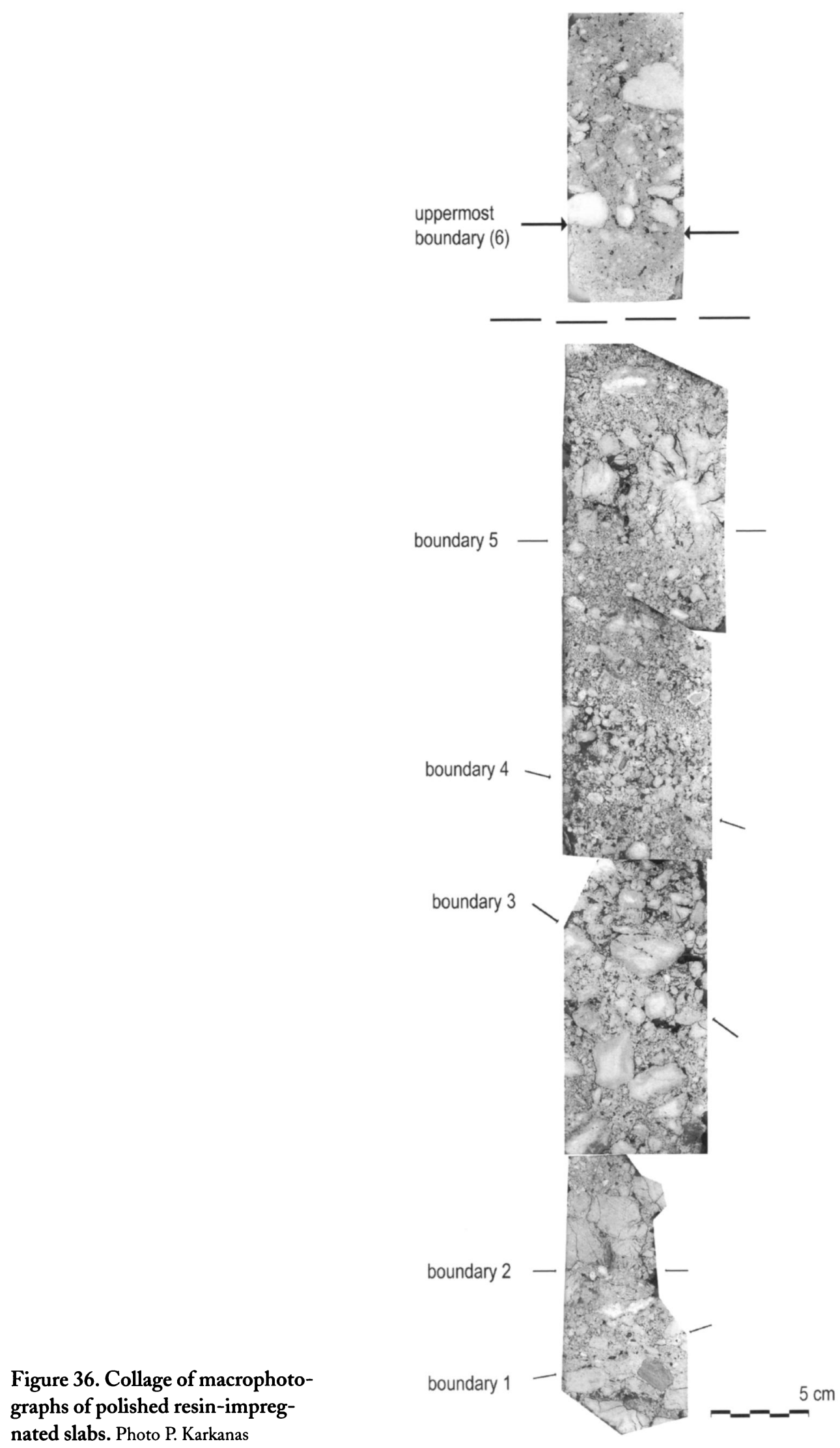




\section{INTERPRETATION}

Taking the field observations and the above features into consideration, we can only conclude that this deposition is the result of several cut-and-fill episodes. Each time the filled dromos was dug out, the previous fill was not completely removed, leaving behind some remnants of it, particularly against the original walls; this explains the up-tilt of some of the sutures. The boundary between the previous fill and the new one is the recorded discontinuity zone. The lower compacted zone with the horizontal fissuring and elongated voids is the trampled surface on which human activity took place before the new refill. Since aggregates of humus soil, clay dust, organic staining, or other extraneous dirt were not observed on the trampled surfaces, we assume that the entrance was not left open for a considerable time. The first increment of the new fill apparently was looser than the old fill, and that marks a suture line. The coarse material characteristic of most of the discontinuity zones (Figs. 34-36) could be the result of detachment and incorporation of large fragments from the exposed walls of the dromos as humans moved about the open tomb. There is also a possibility that the accumulation of the coarse material in the first increment of each fill is the result of a gravitational sorting as the dirt was being thrown into the corridor or an intentional sorting of the filling material by the Mycenaean users of the tomb in an attempt to get rid of the coarse material. However, we will not fully understand all the unintentional sorting procedures that were taking place during the fill of the trench unless we experimentally perform the process.

A very interesting feature is that some of the boundaries mark an abrupt change from a lower, more recrystallized and compacted sediment to a less recrystallized and loose one. This is particularly evident in the lower and uppermost boundaries (Fig. 36). In order for such chemical and physical modification of the sediment to take place after it was deposited, there must have been a considerable passage of time (several years or tens of years?) before it was dug again. The resulting new loose fill contrasts with the remains of the altered old one. Nevertheless, the new fill also changed with time, but the initial suture zone could not be overprinted by continuing physical and chemical modification. At present, we cannot be sure if there is indeed a difference in the time elapsed among the consecutive fills assigned to the two aforementioned boundaries and the other ones. The issue may be resolved if several analogous indications would be consistently recorded for particular boundaries in future sampling.

The preserved profiles record the existence of at least six episodes of filling (see Figs. 28, 29, 36, where they are indicated as boundaries B1, B2, etc.). There is, however, a possibility that some refills did not leave any traces, since they might have been almost completely removed during the next opening of the dromos. The preservation of several superimposed discontinuities in the lower $50-60 \mathrm{~cm}$ of the corridor fill might imply that the first openings were careful and laborious in that the diggers tried to open the entire original corridor each time. The last two times, however, the corridor was only partially opened.

This experiment in analyzing strata in the dromos of a chamber tomb was surprisingly successful in detecting evidence of the openings and 
closings of the tomb, in detecting the precise boundaries of these events, in tracing their slopes, in classifying the different micromorphological features of the deposits, and in providing evidence on which to base hypotheses about the history of human use of the tomb. Further work of this kind is merited to test if these observations hold true in different chamber tomb settings. ${ }^{40}$ Although, as noted above, other excavators have detected multiple strata in the dromoi of chamber tombs, it is likely that they did not discover each and every one. Our attempts to identify strata visually-both in the process of excavation and through inspection of the preserved balk that cut through the dromos (Fig. 27) - did not lead us to recognize all of the strata that Karkanas could identify from thin sections that he impregnated with resin and studied visually and microscopically after they had been cut. Of particular importance is the prospect of a "geological signature" for the different kinds of filling (loose fill, more compacted fill, and discontinuity zones with occasional compacted surfaces). From a geological and archaeological perspective, it is extraordinary to realize that such brief episodes of human behavior can be detected. Such exceptionally fine-grained analysis of temporally brief activity holds open the door for many applications in the recovery and interpretation of cultural and natural processes in the archaeological record. ${ }^{41}$

\section{PALAEOBOTANICAL INVESTIGATIONS}

Samples were systematically collected for flotation using a water sieve in order to recover remains of any nature, but especially archaeobotanical ones, for analysis. The deposition of plant remains, whether fortuitous or purposeful, offers a chance to study mortuary behavior and to think about ways in which the local environment related to the use of the tomb. Naturally, the highly disturbed nature of the excavated tomb prevented systematic collection, except from the undisturbed dromos, and this resulted in the acquisition of an extremely sparse assemblage, which is insufficient for meaningful interpretation of the archaeobotany of the tomb.

The majority of species found were part of the natural vegetation around the tomb and include Lithospermum arvense and representatives of the genera Schoenus and Juncus, as well as members of the Boraginaceae family that could not be identified any further due to their poor preservation. Economic species (Triticum/Hordeum sp., Vitis vinifera, and Olea europaea) were present in the dromos samples but their numbers were insignificant, totaling only a few individuals, which most likely represent residual accumulations rather than deliberate deposition. The disturbed nature of the dromos deposit and the numerous roots present in the soil samples add further support to such an interpretation.

40. See n. 35, above; Boyd (2002, p. 63) discusses the question of the filling of dromoi and observes that Taylour (Palace of Nestor III, pp. 98, 101) noted four episodes of opening of the Englianos tholos tomb, largely because he sectioned the dromos lengthwise.
Taylour (p. 100) also recorded multiple episodes in the block wall of the stomion, and in the excavation of chamber tomb E6 he observed at least five different openings on the basis of strata visible in the dromos (p. 184, fig. 339).

41. Schiffer 1983. 


\section{CONCLUSIONS}

The primary goal of the first season at Barnavos was to excavate the robbed tomb, explore the area around it for other tombs, and develop a strategy and method for a full-scale project. The long-term goal was the recovery and study of human skeletal remains in order to understand the human biology and demography of the Late Bronze Age community in the valley. The extreme disturbance of the tomb by clandestine robbers and the absence of any other tombs in the area frustrated the achievement of these goals, but not entirely, and the excavation planned for the cemetery at Ayia Sotira offers another chance for their realization.

Despite the tomb's disturbance, several conclusions can be drawn from this research. First is the importance of using soil science and micromorphology for examining archaeological contexts, which also holds open the promise that other scientific applications should be utilized as well. Second, the careful application of a strict method of collecting and documenting the remains demonstrates that much useful information can be gained even from highly disturbed deposits. Third are the general conclusions to be drawn with respect to the cultural practice of burial and the spatial relations of mortuary places to settlement.

Michael Schiffer has claimed that archaeologists must differentiate between natural transformations of the archaeological record and cultural ones, and that a consequence of this realization is that all kinds of disturbances up to the present and including those of the excavator need to be taken into account. ${ }^{42}$ Negative observations, therefore, are as important as positive ones. We had hoped to be able to recover the original ground surface, and we postulated that a combination of geomorphological work with recovery of phytoliths would permit us insight into the nature of the original surface, its slope, its soil, and vegetation. Instead, we were forced to recognize that the creation of a terrace within the last 30 years in the northern part of the area in which the tomb is located had cut away much of the topsoil and, through the action of deep plowing, had even removed much of the caliche palaeosol into which the tomb was cut.

It is apparent, however, that these modern mechanical depredations did not extend farther than the area of the tomb because a channel cut into the caliche was found northwest of it (N238-242 E683-687); in the same general region a Roman lamp fragment (34) was found, while to the north a jar fragment (35) and a coin of Justin II (A.D. 565-578 [36]) turned up, suggesting Late Roman-Early Christian activity in the area ${ }^{43}$ Presumably the channel was used to bring water down the slope for irrigation, perhaps water from the dried-up spring at the top of the ravine. The channel is likely to indicate ancient farming activity that might already have disturbed or removed the Late Bronze Age ground surface around the tomb. The clearing of the end of the dromos also showed that the deep plow stopped just short of it, as the lip of the dromos was perfectly preserved; but without doubt the original soil there was no longer present (Fig. 5). Hence, our hopes of finding a soil surface contemporary with the tomb were dashed, and with them any chance of recovering information about mortuary practices that may have taken place outside the tomb.
42. Schiffer 1995.

43. For contemporary farming activity in the Sanctuary of Zeus associated with an Early Christian settlement in the valley, see Miller 1980; 1988, pp. 3-8. 
Of all the scientific procedures we employed, the micromorphological investigation was the most successful. As noted above, these results provided important information about the use of the tomb. If we accept that the dromos was opened at least six times, then it is necessary to question if each opening was for the deposition of a new burial or for some rite associated with memorials. ${ }^{44}$ Although it is not possible with the limited evidence available to answer this question, it is useful to observe that the strata that record these openings are progressively steeper for each successive opening, such that the last was cut into the dromos from high up, probably not far from the top of the stomion facade (Figs. 27, 28, 36). Our demonstration that the strata of these multiple openings are successive explains why it was so difficult to recognize these layers during excavation. Rising soil surfaces, especially if they strike the surface at nearly 45 degrees and consist of the same soil components as those around them, are not likely to be identified, even by the most experienced excavator, and if so, would be very difficult to follow to their termination.

As noted by Karkanas in the geomorphological discussion above, some of these surfaces show evidence of compaction, presumably the trace of humans trampling the surface as they went in and out of the tomb, while others are either loose or compact fills associated with refilling the dromos. An inclined surface should manifest pebble and gravel accumulations that have slid downslope, and these will be mixed with the natural sorting that occurs when the backfill is being shoveled into the dromos as it is refilled. At that same time, artifact and organic debris from contemporary and previous openings of the tomb will be reintroduced. This means that any single stratum of the dromos, except perhaps the lowest one, can be expected to contain a mixture of material deposited from previous openings. When a tomb is reopened to place a new burial in the chamber, we assume that there is some disturbance of the original burials. They may be undisturbed if there is room in the chamber for the next burial, but, as frequently noticed, ${ }^{45}$ they

44. Cavanagh 1978; Wells 1990, p. 136.

45. Cavanagh 1978.

46. Blegen 1937, pp. 237-238, 242, 258-259; Persson in Frödin and Persson 1938, p. 358; Persson 1942, p. 32; Deshayes 1966, p. 244; Demakopoulou 1990, p. 122; Cavanagh and Mee 1998, pp. 72-74, 115; Boyd 2002, p. 90.

47. See n. 12, above; noted recently at Kokla in Demakopoulou 1990, pp. 113, 115, and fig. 2. Alternatively, unpainted drinking vessels in the dromos may have been nothing more than the detritus of consumption by workers while reopening the dromos, although, for a strong argument of this practice being linked to the worship and honor of the dead, see Gallou 2005, pp. 129-140. p. 115.
48. Cavanagh and Mee 1998, are heaped together and either shoved aside or reburied; sometimes a new level is created over the first burials. When any of these occur, it is probable that some of the contents are also disturbed. Pots may be broken or offerings pilfered, and these may also be scattered into the dromos. With this in mind, it is important to consider the distribution of pottery we recovered in the dromos, the disturbed chamber, and the spoil heap.

As Dabney has argued above in her discussion of the pottery, there appears to be a sharp differentiation between the deposition of closed and pattern- or linear-painted vessels and those of open, unpainted ones. As others have done before, ${ }^{46}$ she suggests that this is a reflection of mortuary practice for which it was customary to leave with the deceased closed and painted vessels (from large storage or serving vessels to small ones that might have held unguents or perfumes), while the deposition of open, unpainted drinking vessels is evidence of post-burial activities, including drinking or libating to the dead and leaving or smashing the cups in the dromos. ${ }^{47}$ As Cavanagh and Mee observe, this practice is not universal, ${ }^{48}$ but it seems clearly to be widespread in the northeastern Peloponnese. The clarity of this distinction in the tomb at Barnavos, despite its disturbance and despite the mixing of material from different episodes of opening, 
strongly confirms this hypothesis. Insofar as this practice is common in the Argolid and the Corinthia, its recognition at Tsoungiza is yet another sign of the extent to which this settlement had been drawn into the political economy and socio-ideological orbit of the powerful center at Mycenae.

Despite the enormous amount of information gained from the excavation of Tsoungiza and survey of the valley, ${ }^{49}$ there are few indications of how wealthy the inhabitants were as judged by imported craft items, ${ }^{50}$ because these are normally found in tombs. Likewise, without skeletal remains, grave goods, and other information from mortuary deposits, it is not possible to judge health, genetic makeup, and social structure. To a limited extent the excavation of the tomb at Barnavos throws some light on these matters. We will never know whether the tomb robbers made away with any objects that would be regarded as evidence of wealth. The discovery of a bronze razor (5) and a serpentine conical bead (12) suggests that the burying group of this tomb were like many other persons living in the countryside around Mycenae. ${ }^{51}$ Pappi's excavation of the tomb at Ayia Sotira seems to confirm this, as it contained pottery, stone beads, and a bronze knife that compare well with finds from "average" tombs at Aidonia and Zygouries. ${ }^{52}$ Although the extreme destruction and dispersal of the skeletal remains prohibits detailed observations, Triantaphyllou did not notice anything in the limited remains (e.g., the teeth) that signals any chronic health or diet problems. Further work on these questions will be pursued in the continuing excavations planned at Ayia Sotira.

The Barnavos tomb was probably very much like those excavated by Blegen at nearby Zygouries, which were of similar size and did not contain evidence of wealth. ${ }^{53}$ All of these tombs are modest in form and size, and they display none of the special features noted in the more grandiose tombs at Aidonia, let alone those of Mycenae, Prosymna, Dendra, Argos, Nauplion, and Asine, to cite well-known examples in the general region. They also all date within the period LH IIIA2-IIIB2, and this seems equally the case for the large chamber tomb cemetery at Aidonia. ${ }^{54}$ The small number of chamber tombs of LH II date or earlier in this area (and generally outside of Mycenae) is striking. ${ }^{55}$ Perhaps the spread of the chamber tomb as a burial form is related to the assertion of territorial power by Mycenae. For the Nemea Valley this proposition remains to be tested. Anticipated further excavation of the new cemetery at Ayia Sotira (salvaged in 2002 by Pappi) may help answer this question and aid our understanding of the larger context of mortuary behavior in the Nemea Valley during the Mycenaean period.

Scholars have proposed a number of factors that may have affected the location of a Mycenaean chamber tomb cemetery. ${ }^{56}$ Considerations of local topography (such as proximity to the associated settlement) and geomorphology (such as the need for suitably soft bedrock but hard enough and of uniform structure so as not to collapse) are considered decisive, but social and political factors may also have been important. ${ }^{57}$ Many reasons have been proposed for the location of tombs away from the settlement. There is no rule that can guide the archaeologist, but rather a variety of factors need to be considered, and a comparative study that takes into
49. Wright 1982, 1990; Wright et al. 1985, 1990; Cherry and Davis 2001. 50. Dabney 1997; Burns 1999, pp. 101-114, 177-187.

51. Cf. chamber tombs XXXIII and XXXV at Zygouries (Blegen 1928, pp. 57-64); see also Voutsaki 1995 , pp. 58-59; Sjöberg 2004.

52. For a complete description of this tomb, see Pappi 2005.

53. Blegen 1928 , pp. 57-64, 171-174.

54. Kaza-Papageorgiou 1996, p. 38.

55. Although some of the pottery from tombs at Aidonia (e.g., tomb 6) is dated to LH IIB and LH IIIA1, until full publication of the cemetery, it is unclear if any of the tombs date as early as LH II. This phenomenon is discussed by Cavanagh and Mee (1998, p. 125).

56. See Cavanagh and Mee 1990; Dabney 1999; Boyd 2002, pp. 58-66, 93-96; Shelton 2003, p. 35.

57. Cavanagh and Mee (1998, pp. 42-43) are skeptical of most of these factors; see also Parker Pearson 1999, pp. 124-141; and cf. Tainter 1978. 
account contemporary and related situations is necessary in order to come to any conclusion. ${ }^{58}$ Issues we think important to consider are the relation of tombs to notional properties or territories, their location alongside roads for reasons of accessibility, their visibility, concerns about pollution, relation to places of habitation, and customs obtaining elsewhere, notably in the political capital of Mycenae. ${ }^{59}$

The Argolid is the most thoroughly investigated area of the Mycenaean world, and the analysis of cemeteries there has revealed how complex mortuary evidence is. As Cavanagh and Mee have observed, there is no obvious spatial pattern. ${ }^{60}$ Conversely, Late Helladic burial sites in the Corinthia are for the most part almost all small or unpublished, providing therefore only fragmentary mortuary data and an incoherent picture of the region as a whole. ${ }^{61}$ When we consider mortuary practices as a social strategy, it seems likely that the structure of relations within a community and wider societal concepts will have influenced the choice of site for the establishment of a cemetery, the form of burials within it, and their placement.

As is typical in the Mycenaean world, the tombs at Barnavos and Ayia Sotira are located on sloping ground and separated from the settlement by distance (here about $1 \mathrm{~km}$ ) and topography, usually near a ravine or watercourse. Both are close to water sources. The burial sites also lie at a distance of $1,400 \mathrm{~m}$ from each other, roughly forming an equilateral triangle in relation to the settlement. Both locations are at about the same elevation (Barnavos at 368-370 masl, Ayia Sotira at 354-360 masl), roughly the same as that of the settlement on Tsoungiza (between 360 and 370 masl). As far as we are able to determine, all of the tombs are oriented toward Tsoungiza, although the position of the dromos in each instance is as much a factor of the slope into which each was cut as any other reason. The settlement itself is located on the eastern and southeastern slopes of the hillside: in other words, its back is to the known tombs. If no tombs are located east or south of Tsoungiza, this would be a significant indicator of spatial relationship, as already remarked upon elsewhere by Berit Wells. ${ }^{62}$

The presence of at least two disposal areas has potential social, political,

58. See Cavanagh and Mee 1990; 1998, pp. 55, 65-69; Dabney 1999; Parker Pearson 1999; Boyd 2002, pp. 58-61.

59. See Shelton 2003; also Parker Pearson's review (1999, pp. 124-141) of different issues in assessing the placement of burials in a landscape.

60. Cavanagh and Mee 1990; 1998, pp. 61-62; Mee and Cavanagh 1990, p. 227.

61. Chamber tombs have been excavated at Zygouries (Blegen 1928, pp. 57-65), Corinth (Vanderpool 1954, p. 232), Krines (Krystalli-Votsi 1969), Perachora (Hatzipoulou 1988), Kato Almyri (Banaka-Dimaki 1988), and Aidonia (Krystalli-Votsi 1986; Demakopoulou 1996).

62. Wells 1990, pp. 127-128. and economic implications for continuing research. Aside from consideration of their spatial relationship to the community, we are interested in understanding if the tomb locations reflect such social relations as status differentiation or social groupings, whether kin or cross-cutting. As they are placed near areas of good arable land, we wish to understand if they represent claims to property or other rights to the landscape. It is possible that these locations represent a temporal shift marked by the abandonment of Barnavos as an unsuitable location. This seems, however, less likely in view of the multiple reopenings of the tomb at Barnavos. We prefer the notion that the group that used this tomb either died out or began burying elsewhere for some reason.

No matter what the reason, the multiple use of the Barnavos tomb is in agreement with the evidence from other Mycenaean chamber tomb cemeteries - that they were locations of memorializing rituals. These cemeteries were no doubt sacred places inhabited by close relations and ancestors of the burying group. To point to them would have been a powerful way to assert 
one's historical position within the local society. This fact, taken together with the relative equidistance and equal elevation of the tombs at Barnavos and Ayia Sotira with the settlement on Tsoungiza, defines a probable conceptual distance of the dead from the living. We wonder if this relates both to political and economic concerns about territory (either of the community of Tsoungiza or merely that of the individual burying groups) and to conceptual boundaries, such as pollution. ${ }^{63}$ The placement of cemeteries near probable sources of water may relate to notions about purification. ${ }^{64}$ Equally, there are cultural factors that influence the siting of cemeteries; important among these are local and regional customs, land use (especially areas of cultivation), routes of communication and transport, and boundaries. ${ }^{65}$

Since Tsoungiza was occupied from the late Middle Helladic (MH) period until the end of LH IIIB (a span of ca. 400-500 years), we hypothesize a considerable burial population. For example, if there were five to seven families living on Tsoungiza from the time of its resettlement at the end of the MH period down through LH II, and 10 to 15 during LH III, then the total number of burials might be estimated to be between 150 and $200 .{ }^{66}$ As Dabney has already argued, ${ }^{67}$ there may be a number of chamber tomb cemeteries connected with the settlement. These could be located in several areas, for example, on different lands held by different family and kin groups, or by groups separated by status.

In addition, there are no doubt many cist graves from the MH III-LH II span, some within the settlement, others perhaps lying undiscovered around the slopes of Tsoungiza hill. Perhaps then the placement of chamber tomb cemeteries in the valley defined both a sacred and social space for the community, one known primarily through the day-to-day practice of tending the fields or traveling to neighboring communities in the next valley, but regularly punctuated by commemorative moments when the newly dead occasioned a reopening of the chambers and a remembrance of others buried there. The burial procession from Tsoungiza across to one of these burial sites would have tied the familiar landscape together, and the view from the burial locale across the valley encompassed the settlement and other places where the community buried its dead, as well as its economic domain and probably its primary sphere of social activity.

One result of the Nemea Valley Archaeological Project was a renewed focus on the apparent absence in the Corinthia of a major settlement with a palace that would have dominated the region. ${ }^{68}$ Jeremy Rutter suggested,

63. According to Douglas (1984, p. 5), notions of pollution are stressed in times of fluid and fragile social conditions and express anxiety about both the internal divisions and the external boundaries of a community. Wells (1990, pp. 136-138) and Boyd (2002, p. 63) express skepticism that pollution was a concern to those burying in chamber tombs.

64. See Hertz 1960; van Gennep 1960; Voutsaki 1993; Cavanagh and
Mee 1998; Dabney 1999; Parker Pearson 1999, pp. 24, 126-128.

65. See Shelton 2003, p. 35; also Boyd 2002, pp. 33-48, esp. pp. 47-48, noting the lower number of chamber tomb cemeteries in Messenia compared to the northeastern Peloponnese.

66. This calculation is based upon the formula used by Broodbank (1989, p. 323); we estimate about five families between MH III through LH II, perhaps seven to 10 between LH IIIA1 and LH IIIA2, and at least 10 throughout LH IIIB. We calculate about 500 years between the beginning of settlement and its abandonment at the end of LH IIIB.

67. Dabney 1999.

68. See Blegen 1928, p. 221; Bintliff 1977, pp. 346-347; Vermeule 1987; Davis 1988; Wright 1990, 2004; Isthmia VIII, pp. 352-353; Pullen and Tartaron 2007. 
on the basis of his study of the ceramic evidence, that at the time of the resettlement of Tsoungiza at the end of MH III, the settlers there did not seem to have been much in contact with or under the control of the fastemerging settlement at Mycenae or any other of the settlements in the Argolid. ${ }^{69}$ By LH IIA the picture had changed and the people at Tsoungiza were consuming fine tableware from Mycenae. ${ }^{70}$ This view is confirmed by Dabney, who considers the settlement during LH III to be entirely tied into Mycenae's political economy. ${ }^{71}$ Still, the question of whether and when the Nemea Valley or the Corinthia came under the control of the Argive centers has to remain open, because new evidence-particularly the rich finds from the chamber tomb cemetery of Aidonia near Nemea, in the view of Pappi-provides some indication for the relative autonomy of this area. ${ }^{72}$ The comparative analysis of Late Helladic mortuary behavior and domestic data in the Nemea Valley is expected to shed new light on the problem and lead to the reassessment of the position of the settlement in the regional hierarchy and the network of relations in which it might have been involved.

Although it is premature to draw any firm conclusions, these considerations and questions provide working hypotheses for continuing research. This project aims to continue the analysis of Late Bronze Age mortuary behavior in the valley at the level of the associated cemeteries and in terms of their size and spatial organization. The resulting understanding of similarities and differences of the organization and structure of the different cemeteries and the comparison of mortuary with domestic data from the site will provide important insights into the history and social structure of settlement on Tsoungiza and into the relationships its occupants had to the land and landscape in the Nemea Valley.

\section{ACKNOWLEDGMENTS}

This report is dedicated to the memory of Persephone Galani, whose untimely death in 2004 cut short her career and participation in our project.

We wish to thank the following for their assistance in launching this cooperative project: Alexandros Mantis, Ephor, 4th Ephorate of Prehistoric and Classical Antiquities, Ministry of Culture; James Muhly and Stephen Tracy, Directors, and Maria Pilali, Administrative Secretary, ASCSA. We are indebted to the chair (Leslie Preston Day) and the members of the

69. Rutter 1990, pp. 452-455.

70. Rutter 1993, pp. 88-91.

71. Dabney 1997; see also Davis 1988; Wright 1990, 2004; Cherry and

Davis 2001; Dabney, Halstead, and Thomas 2004, pp. 213-214.

72. The recent discovery of the possibly associated LH settlement remains at Platana, about $500 \mathrm{~m}$ northwest of the chamber tombs at Aidonia, safely separated from the cemetery by the deep Platanorema ravine, opens new possibilities for the comparative study of mortuary and settlement data (see Pappi 2005). In his study of settlement distribution in the northeastern Peloponnese, Wright (2004, pp. 125128) suggests that Aidonia may have been sufficiently strong to maintain some independence from Mycenae. 
Excavation and Survey Committee of the ASCSA for recognizing the need to provide on short notice a permit for this rescue operation. Help was also provided by Guy Sanders, Director, Corinth Excavations, and Kim Shelton, Mycenae Excavations. Vassilis Skazas and Maria and Panayiotis Fountoukos graciously permitted us to work in their fields while expropriations were proceeding. Tryphonas Mangioros, President of the village of Ancient Nemea, and the Agricultural Cooperative of Ancient Nemea made municipal facilities available. We are grateful to Vassilis and Athanasios Skazas for their cooperation in 2003, when they provided us with written permission to test in their field. We also thank Sherry Fox, Director of the Wiener Laboratory, ASCSA, and Evangelia Kyriatzi, Director of the Fitch Laboratory, British School of Archaeology, who provided logistical support and advice.

The following assisted in excavation and study: Persephone Galani from the 4th Ephorate of Prehistoric and Classical Antiquities, Nauplion; Kalliopi Eukleidou, Rania Exarchou, Eleni Milka, and Ioanna Papamagkana from the University of Thessaloniki; Bridget Algee, Joanna ChejadeBloom, Rosemary Kovacs, Valeriya Kozlovskaya, and Jessica Miller from Bryn Mawr College; Elizabeth Monroe from Haverford College; and Peter Wright from Friends Central School (Philadelphia). Dimitris Niteros of Ancient Nemea served ably as foreman.

The project was supported by the Institute for Aegean Prehistory (INSTAP) with a major grant. Wright received a Senior Faculty Summer Research Stipend from the National Endowment for the Humanities. The Hetty Goldman Fund, Bryn Mawr College, funded equipment purchases. We especially thank James and Terry Miller for their generous support in 2002 and 2003 and for providing funds for land purchases at Barnavos and Ayia Sotira. 


\section{REFERENCES}

Åström, P. 1977. The Cuirass Tomb and Other Finds at Dendra (SIMA 4), Göteborg.

Banaka-Dimaki, A. 1988. "Kó $\tau \omega ~ A \lambda-$

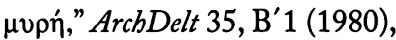
pp. 102-105.

Bintliff, J. L. 1977. Natural Environment and Human Settlement in Prebistoric Greece, Based on Original Fieldwork (BAR Suppl. 28), Oxford.

Blegen, C. W. 1928. Zygouries: A Prebistoric Settlement in the Valley of Cleonai, Cambridge, Mass. 1937. Prosymna, the Helladic Settlement Preceding the Argive Heraeum, Cambridge.

Boddington, A., A. N. Garland, and R. C. Janaway, eds. 1987. Death, Decay, and Reconstruction: Approaches to Archaeology and Forensic Sciences, Manchester.

Boyd, M. J. 2002. Middle Helladic and Early Mycenaean Mortuary Practices in the Southern and Western Peloponnese (BAR-IS 1009), Oxford.

Broodbank, C. 1989. “The Longboat Society in the Cyclades in the KerosSyros Culture," AJA 93, pp. 310337.

Brothwell, D. R. 1981. Digging UP Bones: The Excavation, Treatment, and Study of Human Skeletal Remains, 3rd ed., London.

Buikstra, J. E., and D. H. Ubelaker, eds. 1994. Standards for Data Collection from Human Skeletal Remains. Proceedings of a Seminar at the Field Museum of Natural History, Organized by Jonathan Haas, Fayetteville, Ark.

Burns, B. 1999. "Import Consumption in the Bronze Age Argolid (Greece): Effects of Mediterranean Trade on Mycenaean Society" (diss. Univ. of Michigan).

Cavanagh, W. G. 1978. "A Mycenaean Second Burial Ritual?" BICS 25, pp. 171-172.

. 1987. "Cluster Analysis of Mycenaean Chamber Tombs," in Thanatos: Les coutumes funéraires en Egée à l'âge du bronze. Actes du Colloque de Liège, 21-23 avril 1986 (Aegaeum 1), ed. R. Laffineur, Liège, pp. 161-169.
Cavanagh, W. G., and C. Mee. 1990. "The Location of Mycenaean Chamber Tombs in the Argolid," in Hägg and Nordquist 1990, pp. 55-64.

1998. A Private Place: Death in Prehistoric Greece (SIMA 125), Jonsered.

Cherry, J., and J. Davis. 2001. "Under the Sceptre of Agamemnon': The View from the Hinterlands of $\mathrm{My}-$ cenae," in Urbanism in the Aegean Bronze Age (Sheffield Studies in Aegean Archaeology 4), ed. K. Branigan, London, pp. 141-159.

Cherry, J. F., J. L. Davis, and E. Mantzourani. 1996. “The Nemea Valley Archaeological Project, Archaeological Survey: Internet Edition," http://river.blg.uc.edu/nvap/ (accessed May 2004).

Courty, M. A., P. Goldberg, and R. Macphail. 1989. Soils and Micromorphology in Archaeology, Cambridge.

Dabney, M. K. 1997. “Craft Product Consumption as an Economic Indicator of Site Status in Regional Studies," in TEXNH: Craftsmen, Craftswomen, and Craftsmanship in the Aegean Bronze Age. Proceedings of the 6th International Aegean Conference (Aegaeum 16), ed. R. Laffineur and P. P. Betancourt, Liège, pp. 467-471.

. 1999. "Locating Mycenaean

Cemeteries," in Meletemata: Studies in Aegean Archaeology Presented to Malcolm H. Wiener as He Enters His 65th Year (Aegaeum 20), ed. P. P. Betancourt, V. Karageorghis, R. Laffineur, and W.-D. Niemeier, Liège, pp. 171-175.

Dabney, M. K., P. Halstead, and P. Thomas. 2004. "Mycenaean Feasting on Tsoungiza at Ancient Nemea," Hesperia 73, pp. 197215.

Davis, J. L. 1988. “If There's a Room at the Top, What's at the Bottom? Settlement and Hierarchy in Early Mycenaean Greece," BICS 35, pp. 164-165.

Demakopoulou, K. 1990. "The Burial Ritual in the Tholos Tomb at Kokla, 
Argolis," in Hägg and Nordquist 1990, pp. 113-123.

, ed. 1996. The Aidonia Treasure:

Seals and Jewellery of the Aegean Late Bronze Age, Athens.

Deshayes, J. 1966. Argos, les fouilles de la Deiras, Paris.

Douglas, M. 1984. Purity and Danger: An Analysis of Concepts of Pollution and Taboo, London.

Frödin, O., and A. W. Persson. 1938. Asine: Results of the Swedish Excavations, 1922-1930, Stockholm.

Furumark, A. [1941] 1972. The Mycenaean Pottery 1: Analysis and Classification (SkrAth $\left.4^{\circ}, 20\right)$, repr. Stockholm.

Gallou, C. 2005. The Mycenaean Cult of the Dead (BAR-IS 1372), Oxford.

Goodman, A., and G. Armelagos. 1985. "Factors Affecting the Distribution of Enamel Hypoplasias within the Human Permanent Dentition," American Journal of Physical Anthropology 98, pp. 479-493.

Goodman, A., G. Armelagos, and J. Rose. 1980. "Enamel Hypoplasias as Indicators of Stress in Three Prehistoric Populations from Illinois," Human Biology 52, pp. 515-528.

Hägg, R., and G. C. Nordquist, eds., 1990. Celebrations of Death and Divinity in the Bronze Age Argolid. Proceedings of the Sixth International Symposium at the Swedish Institute at Athens, 11-13 June 1988 (SkrAth 4', 40), Stockholm.

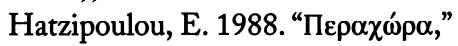
ArchDelt 35, B'1 (1980), pp. 109110.

Hertz, R. 1960. Death and the Right Hand, New York.

Hillson, S. 1996. Dental Anthropology, Cambridge.

Iezzi, K. 2001. "Skeletal Materials Shed Light on Environmental and Social Conditions," American School of Classical Studies at Athens Newsletter 46, pp. 14-15.

Isthmia VIII = C. Morgan, The Late Bronze Age Settlement and Early Iron Age Sanctuary (Isthmia VIII), Princeton 1999.

Kaza-Papageorgiou, D. 1996. "Finds from the Excavations of the Mycenaean Cemetery of Aidonia, 19781980," in Demakopoulou 1996, pp. 36-67.
Knapp, R. C., and J. D. Mac Isaac. 2005. Excavations at Nemea III: The Coins, Berkeley.

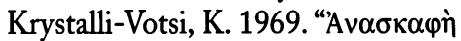

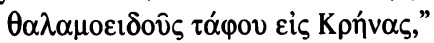
ArchDelt 22, B'2 (1967), pp. 163164.

. 1986. "Т $\alpha \delta \alpha \kappa \tau \nu \lambda i ́ \delta 1 \alpha \alpha \pi$ $\tau \alpha$

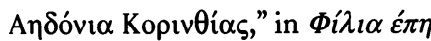

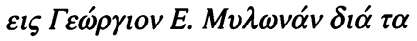

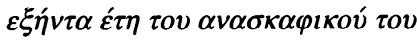

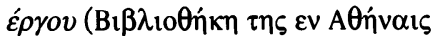

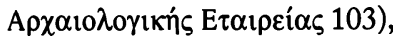
Athens, pp. 34-43.

Littleton, J. 2000. “Taphonomic Effects of Erosion on Deliberately Buried Bodies," JAS 27, pp. 5-18.

Lyman, R. L. 1994. “Quantitative Units and Terminology in Zooarchaeology," AmerAnt 59, pp. 36-71.

Mee, C. B., and W. G. Cavanagh. 1990. "The Spatial Distribution of Mycenaean Tombs," BSA 85, pp. 225-244.

Miller, S. P. 1980. "Excavations at $\mathrm{Ne}-$ mea, 1979," Hesperia 49, pp. 178205.

1988. "Excavations at Nemea, 1984-1986," Hesperia 57, pp. 120.

Nawrocki, S. 1995. "Taphonomic Processes in Historic Cemeteries," in Bodies of Evidence: Reconstructing History through Skeletal Analysis, ed. A. L. Grauer, New York, pp. 4966.

Palace of Nestor III = C. W. Blegen, M. Rawson, W. Taylour, and W. Donovan, The Palace of Nestor at Pylos in Western Messenia III: Acropolis and Lower Town: Tholoi, Grave Circle, and Chamber Tombs. Discoveries outside the Citadel, Princeton 1973.

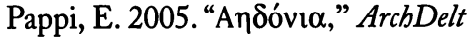
54 B'1 (1999), pp. 148-149.

Parker Pearson, M. 1999. The Archaeology of Death and Burial (Texas A\&M University Anthropology Series 3), College Station, Tex.

Persson, A. W. 1931. The Royal Tombs at Dendra near Midea, Lund.

- 1942. New Tombs at Dendra near Midea, Lund.

Protonotariou-Deïlaki, E. 1966. "Av $\alpha$ -

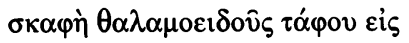
Mvкท́vas," ArchDelt 19, B'1 (1964), pp. 118-121. 
Pullen, D. J., and T. F. Tartaron. 2007. "Where's the Palace? The Absence of State Formation in the Late Bronze Age Corinthia," in Rethinking Mycenaean Palaces II, rev. and expanded 2nd ed. (Cotsen Institute of Archaeology at UCLA, Monograph 60), ed. M. L. Galaty and W. A. Parkinson, Los Angeles, pp. 146-158.

Rutter, J. B. 1990. “Pottery Groups from Tsoungiza of the End of the Middle Bronze Age," Hesperia 59, pp. 375-458.

- 1993. "A Group of Late Helladic IIA Pottery from Tsoungiza," Hesperia 62, pp. 53-93.

Schiffer, M. B. 1983. "Toward the Identification of Formation Processes," AmerAnt 48, pp. 675706.

- 1995. Behavioral Archaeology: First Principles, Salt Lake City.

Shelton, K. 1993. "Tsountas' Chamber Tombs at Mycenae," ArchEph 132, pp. 187-210.

. 2003. "The Chamber Tombs," in Archaeological Atlas of Mycenae

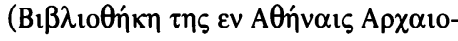

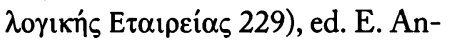
dreadi and L. Braggioti, Athens, pp. 35-38.

Sjöberg, B. L. 2004. Asine and the Argolid in the Late Helladic III Period: A Socio-Economic Study (BAR-IS 1225), Oxford.

Steele, D., and C. Bramblett. 1998.

The Anatomy and Biology of the Human Skeleton, College Station, Tex.

Tainter, J. 1978. “Mortuary Practices and the Study of Prehistoric Social
Systems," in Advances in Archaeological Method and Theory 1, ed. M. B. Schiffer, New York, pp. 105-141.

Thomas, P. M. 2005. “A Deposit of Late Helladic IIIB1 Pottery from Tsoungiza," Hesperia 74, pp. 451573.

Triantaphyllou, S. 2000. "An Assessment of the Potential of Human Bone Studies in Greek Antiquity: Central Greece" (unpublished report, Cardiff University, School of History and Archaeology), Cardiff.

Ubelaker, D. H. 1978. Human Skeletal Remains: Excavation, Analysis, Interpretation, Washington, D.C.

Vanderpool, E. 1954. "News Letter from Greece," AJA 58, pp. 231-241.

van Gennep, A. 1960. The Rites of Passage, trans. M. B. Vizedom and G. L. Caffee, Chicago.

Vermeule, E. 1987. “Baby Aigisthos and the Bronze Age," PCPS 33, pp. 122-152.

Voutsaki, S. 1993. "Society and Culture in the Mycenaean World: An Analysis of Mortuary Practices in the Argolid, Thessaly, and the Dodecanese" (diss. Univ. of Cambridge). .1995. "Social and Political Processes in the Mycenaean Argolid: The Evidence from the Mortuary Practices," in Politeia: Society and State in the Aegean Bronze Age. Proceedings of the 5 th International Aegean Conference (Aegaeum 12), ed. R. Laffineur and W.-D. Niemeier, Liège, pp. 55-64.

Wace, A. 1932. Chamber Tombs at Mycenae (Archaeologia 82), Oxford.

Waldron, T. 1994. Counting the Dead:
The Epidemiology of Skeletal Populations, Chichester.

Wells, B. 1990. "Death at Dendra: On Mortuary Practices in a Mycenaean Community," in Hägg and Nordquist 1990, pp. 125-140.

White, T. D. 2000. Human Osteology, 2nd ed., New York.

Wright, J. C. 1982. "Excavations at Tsoungiza (Archaia Nemea), 1981," Hesperia 51, pp. 375-397. . 1990. "An Early Mycenaean Hamlet on Tsoungiza at Ancient Nemea," in L'habitat égéen prébistorique. Actes de la Table ronde internationale organisée par le Centre national de la recherche scientifique, l'Université de Paris I, et l'École française d'Athènes, Athènes, 23-25 juin 1987 (BCH Suppl. 19), ed. P. Darcque and R. Treuil, pp. 347357.

- 2004. "Comparative Settlement Patterns during the Bronze Age in the Northeastern Peloponnesos, Greece," in Side-by-Side Survey: Comparative Regional Studies in the Mediterranean World, ed. S. E. Alcock and J. F. Cherry, Oxford, pp. 114-131.

Wright, J. C., J. F. Cherry, J. L. Davis,

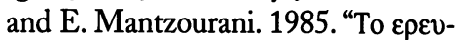

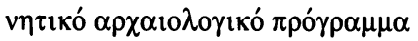

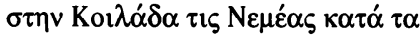

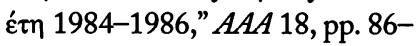
104.

Wright, J. C., J. F. Cherry, J. L. Davis, E. Mantzourani, S. B. Sutton, and R. F. Sutton Jr. 1990. “The Nemea Valley Archaeological Project: A Preliminary Report," Hesperia 59, pp. 579-659.

\section{James C. Wright}

\author{
Bryn Mawr College \\ DEPARTMENT OF CLASSICAL AND \\ NEAR EASTERN ARCHAEOLOGY \\ THOMAS HALL 235 \\ IOI NORTH MERION AVENUE \\ BRYN MAWR, PENNSYLVANIA I9OIO-2899 \\ jwright@brynmawr.edu
}

\author{
Evangelia Pappi \\ 4th Ephorate of Prehistoric and \\ Classical Antiquities \\ CONSTITUTION SQUARE \\ 2 II IO NAUPLION \\ GREECE \\ evapappi@yahoo.gr
}




\section{Sevasti Triantaphyllou}

UNIVERSITY OF SHEFFIELD

SHEFFIELD CENTRE FOR AEGEAN ARCHAEOLOGY NORTHGATE HOUSE

WEST STREET

SHEFFIELD SI 4ET

UNITED KINGDOM

sevitr@otenet.gr

Mary K. Dabney

Bryn Mawr College

DEPARTMENT OF CLASSICAL AND

NEAR EASTERN ARCHAEOLOGY

THOMAS HALL 235

IOI NORTH MERION AVENUE

BRYN MAWR, PENNSYLVANIA I90IO-2899

mdabney@brynmawr.edu

\section{Panagiotis Karkanas}

Ephorate of Palaeoanthropology and SPeleology of Southern Greece 34B ARDITTOU STREET

II6 36 ATHENS

GREECE

pkarkanas@hua.gr

\section{Georgia Kotzamani}

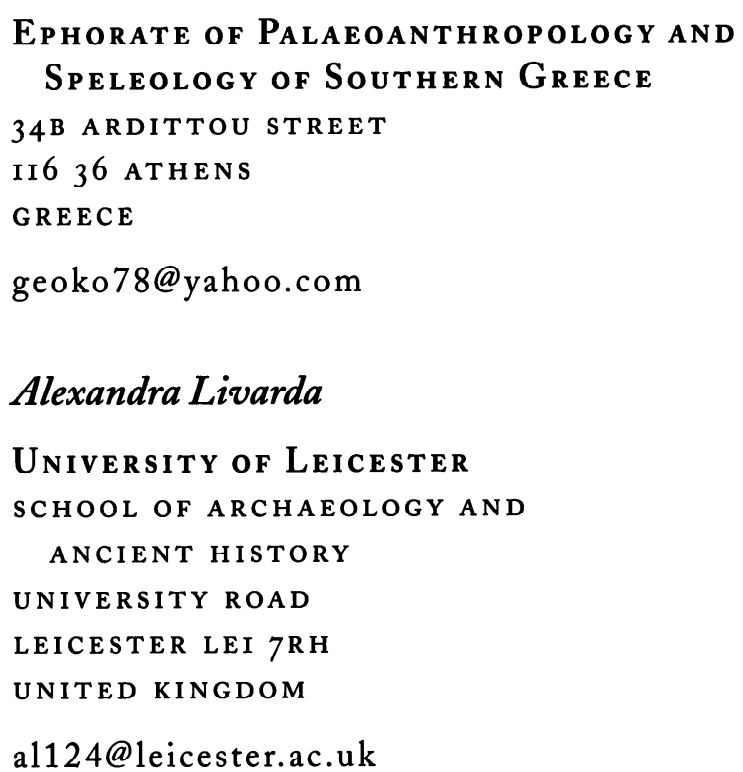

